ARTICLE

https://doi.org/10.1038/s41467-019-11766-w

\title{
Octahedral gold-silver nanoframes with rich crystalline defects for efficient methanol oxidation manifesting a CO-promoting effect
}

\author{
Likun Xiong 1,2,5, Zhongti Sun 1,2,5, Xiang Zhang1,2, Liang Zhao (10) 1,2, Peng Huang ${ }^{1,2}$, Xiwen Chen 1,2, Huidong Jin ${ }^{1,2}$, \\ Hao Sun ${ }^{1,2}$, Yuebin Lian ${ }^{1,2}$, Zhao Deng (1) 1,2, Mark H. Rümmerli ${ }^{1,2}$, Wanjian Yin ${ }^{1,2}$, Duo Zhang 3,4, \\ Shuao Wang ${ }^{3,4} \&$ Yang Peng (i) ${ }^{1,2}$
}

Three-dimensional bimetallic nanoframes with high spatial diffusivity and surface heterogeneity possess remarkable catalytic activities owing to their highly exposed active surfaces and tunable electronic structure. Here we report a general one-pot strategy to prepare ultrathin octahedral $\mathrm{Au}_{3} \mathrm{Ag}$ nanoframes, with the formation mechanism explicitly elucidated through well-monitored temporal nanostructure evolution. Rich crystalline defects lead to lowered atomic coordination and varied electronic states of the metal atoms as evidenced by extensive structural characterizations. When used for electrocatalytic methanol oxidation, the $\mathrm{Au}_{3} \mathrm{Ag}$ nanoframes demonstrate superior performance with a high specific activity of $3.38 \mathrm{~mA} \mathrm{~cm}^{-2}, 3.9$ times that of the commercial Pt/C. More intriguingly, the kinetics of methanol oxidation on the $\mathrm{Au}_{3} \mathrm{Ag}$ nanoframes is counter-intuitively promoted by carbon monoxide. The enhancement is ascribed to the altered reaction pathway and enhanced $\mathrm{OH}^{-}$ co-adsorption on the defect-rich surfaces, which can be well understood from the d-band model and comprehensive density functional theory simulations.

\footnotetext{
${ }^{1}$ Soochow Institute for Energy and Materials Innovations, College of Energy, Soochow University, Suzhou 215006, P. R. China. ${ }^{2}$ Key Laboratory of Advanced Carbon Materials and Wearable Energy Technologies of Jiangsu Province, Suzhou, P. R. China. ${ }^{3}$ State Key Laboratory of Radiation Medicine and Protection, School of Radiation Medicine and Protection, Soochow University, Suzhou 215123, P. R. China. ${ }^{4}$ Collaborative Innovation Center of Radiological Medicine of Jiangsu Higher Education Institutions, Suzhou, P. R. China. ${ }^{5}$ These authors contributed equally: Likun Xiong, Zhongti Sun. Correspondence and requests for materials should be addressed to Z.D. (email: zdeng@suda.edu.cn) or to W.Y. (email: wjyin@suda.edu.cn) or to Y.P. (email: ypeng@suda.edu.cn)
} 
$\mathrm{D}$ irect methanol fuel cell (DMFC) is one of the promising clean and sustainable energy solutions for efficiently converting solar-converted and crop-based chemical energy into electric power ${ }^{1,2}$. As the basic anode reaction of DMFCs, electrochemical methanol oxidation (MOR) has thus received tremendous attentions $s^{3-5}$. As of today, platinum $(\mathrm{Pt})$ based nanomaterials are still considered as the most efficient and widely implemented catalyst for MOR owing to their high affinity to methanol molecules and low activation barriers, both leading to enhanced kinetics of methanol oxidation. However, apart from its high cost, $\mathrm{Pt}$ also has very strong binding affinity to carbon monoxide $(\mathrm{CO})$, one of the dissociation products from methanol oxidation, and even the exposure to a very small quantity of $\mathrm{CO}$ can severely poison the catalyst and thus drastically lower its MOR activity ${ }^{6}$. More recently, intense efforts have been devoted to advance the Pt-based MOR catalysts either by further elevating the specific catalytic activity, or by minimizing the Pt usage, through sophisticated structural and compositional manipulations $^{7-10}$. However, the production cost and the inherent poisoning issue of $\mathrm{Pt}$ remain as challenges to be solved. Other researches have focused on Pd-based catalysts which also manifest fair MOR activities in alkaline electrolytes, but their oxidation to form PdO at similar potentials to MOR, together with the same issue of CO poisoning, limit practical implementation ${ }^{11-14}$.

While gold electrodes have long been studied for electrochemical oxidation of carbon monoxide ${ }^{15-17}$, more studies have been seen recently employing $\mathrm{Au}$ and $\mathrm{Au}$-based nanomaterials as the catalysts for the oxidation of carbonaceous species such as alcohols and carboxylates ${ }^{18-22}$. MOR on these Au-based catalysts has been notoriously plagued with high electrochemical overpotentials and low redox kinetics. In fact, gold is the only metal that has an endothermic oxygen adsorption energy and hence is inert toward most oxidation reactions ${ }^{23}$. To overcome these issues, one important strategy coming to the forefront of $\mathrm{Au}$ catalyst innovations is the design and fabrication of multivariate nanocrystals with tailored geometries and tunable electronic structure, including mesoporous gold-silver networks, nanoporous gold, and hollow gold nanoparticles, etc ${ }^{24-28}$. In such context, $\mathrm{Au}$ nanoframes comprising only vertices and edges offer an appealing option to substitute Pt and Pd-based MOR catalysts by maximizing the utilization of active atoms, electrolyte-accessible surfaces, and surface electronic states ${ }^{29,30}$.

Among the limited reports in synthesizing Au-based nanoframes, a two-step template directed protocol has been typically employed involving the deposition of $\mathrm{Au}$ on the $\mathrm{Ag}$ templates followed by selective Ag etching by oxidants ${ }^{31-33}$. This additional etching step, however, greatly adds to the processing complexity and structural uncertainty, resulting in unsatisfactory material utilization and geometrical control. To circumvent this problem, herein we present a quick one-pot method for the preparation of ultrathin octahedral $\mathrm{Au}_{3} \mathrm{Ag}$ nanoframes with the edge diameters on the order of 5-10 nm and good geometrical uniformity. The reaction intermediates are closely monitored by scanning electron microscopy (SEM) and energy-dispersive X-ray spectroscopy (EDX) to unveil the underlying formation mechanism. Sphericalaberration-corrected TEM (Cs-TEM) is used to perceive lattice details on both the edges and vertices of the alloyed nanoframes, revealing rich crystalline defects as catalytically active sites. As a result, superior MOR activities to the $\mathrm{Pt} / \mathrm{C}$ benchmark are demonstrated with a low-onset potential of $0.3 \mathrm{~V}$ (vs. RHE) and a high specific activity (SA) of $3.38 \mathrm{~mA} \mathrm{~cm}^{-2}\left(950 \mathrm{~mA} \mathrm{mg}_{(\mathrm{Au})}{ }^{-1}\right.$ in mass activity), which, to our best knowledge, are among the highest seen for all Au-based electrocatalysts reported so far (Supplementary Table 8). Moreover, our results show that on the surface of $\mathrm{Au}_{3} \mathrm{Ag}$ nanoframes $\mathrm{CO}$ plays a counter-intuitive role in promoting, rather than poisoning, the methanol oxidation reaction. Such promoting phenomenon is in accordance with Rodriguez's implication about alcohol electro-oxidation on the Au surface in aqueous phases ${ }^{34}$.

\section{Results}

Temporal study on the formation of $\mathrm{Au}-\mathrm{Ag}$ nanoframes. Ultrathin octahedral $\mathrm{Au}-\mathrm{Ag}$ nanoframes with high geometrical uniformity (Fig. 1a, b) were synthesized under nonaqueous condition using chloroauric acid $\left(\mathrm{HAuCl}_{4}\right)$ and silver nitrate $\left(\mathrm{AgNO}_{3}\right)$ as the metal precursors, cetyltrimethylammonium bromide $(\mathrm{CTAB})$ as the structure-directing and complexing agent, octadecylamine (ODA) as the solvent and surfactant, and cuprous chloride $(\mathrm{CuCl})$ as the co-reducing agent (see the Supplementary information for experimental details). To understand the formation mechanism, the growth of the alloyed $\mathrm{Au}-\mathrm{Ag}$ nanoframes was monitored by both SEM and TEM along the reaction course (Fig. 1c-f). Note that $\mathrm{HAuCl}_{4}$ was added at the 36th min from the beginning of the reaction, and prior to that octahedral Ag nanoparticles had already been formed through the reduction of $\mathrm{AgNO}_{3}$ by ODA and $\mathrm{CuCl}$ in the presence of $\mathrm{CTAB}$. Four samples were then collected at the 36th (right before the injection of $\mathrm{HAuCl}_{4}$ ), 38th, 42nd, and 46th min of the reaction for structural and compositional analysis.

Figure 1c present the schematic diagram, SEM, TEM, and EDX mapping images of the octahedral Ag nanoparticles obtained from the first stage of the reaction, in which $\mathrm{CuCl}$ serves as the co-reducing and structure-directing agent for the formation of polyhedrons ${ }^{35,36}$. More importantly, the bromide ions from $\mathrm{CTAB}$ can lower the reduction rate of $\mathrm{Ag}^{+}$, promoting the preferential growth of the (111) facets that possess the lowest surface energy $\left(\gamma_{111}<\gamma_{100}<\gamma_{110}\right)$, and thus lead to the exclusive formation of octahedrons ${ }^{37,38}$. The resulted octahedral $\mathrm{Ag}$ nanoparticles (Ag NPs) have clean and smooth surfaces with an average edge length of $60.8 \pm 4.1 \mathrm{~nm}$ (Supplementary Fig. 1a). Further crystallographic characterizations by X-ray diffraction (XRD) and Cs-TEM indicate the Ag nanoparticles are single crystalline with minimal defects (Supplementary Figs. 2 and 3).

Upon the instant injection of $\mathrm{HAuCl}_{4}, \mathrm{Au}^{3+}$ was first reduced to $\mathrm{Au}^{+}$(rather than $\mathrm{Au}^{0}$ ), which can be stabilized by the bromide ions from $\mathrm{CTAB}$ to form $\mathrm{Au}-\mathrm{Br}$ complexes ${ }^{39,40}$. Comparing to $\mathrm{Au}^{3+}$, the oxidizing potency of $\mathrm{Au}^{+}$is drastically weakened, leading to a more controlled galvanic reaction with $\mathrm{Ag}^{0}$. During the second reaction stage as shown in Fig. 1d, the reactive $\mathrm{Au}^{+}$ were first deposited onto the edges and vertices of Ag octahedrons via galvanic replacement. This selective deposition is synergistically enabled by two obvious facts. First, the low-coordination states of the Ag atoms located at the edges and vertices make them more reactive than those on the flat terraces. Second, the Ag (111) facets are capped by ODA and CTAB, resulting in significantly passivated surfaces. The products obtained from this stage are bimetallic octahedral nanoparticles, with the average edge length increased to $65.9 \pm 3.9 \mathrm{~nm}$ at the 38th minute (Supplementary Fig. 1b).

The deposited Au accumulating on the edges and vertices of the $\mathrm{Ag}$ octahedra gradually forms a natural defense, effectively shielding the underlying Ag atoms from being further oxidized as the reaction goes on. Thus, the newly reduced $\mathrm{Au}^{+}$tend to attack those less-passivated areas, leading to the formation of pinholes on the crystal surfaces. A galvanic cell is thus formed between the outer $\mathrm{Au}$ cathode and the inner Ag anode, whereat silver atoms are oxidized and each provides one electron to reduce one $\mathrm{Au}^{+41}$. Since the outside $\mathrm{Ag}$ (111) facets are capped by ODA and $\mathrm{CTAB}$, the released electrons tend to migrate to the edges and vertices, where $\mathrm{AuCl}^{2-}$ are reduced to $\mathrm{Au}$ (the cathode reaction). The liberated $\mathrm{Ag}^{+}$ions, after reacting with $\mathrm{Cl}^{-}$, and $\mathrm{Br}^{-}$, are 

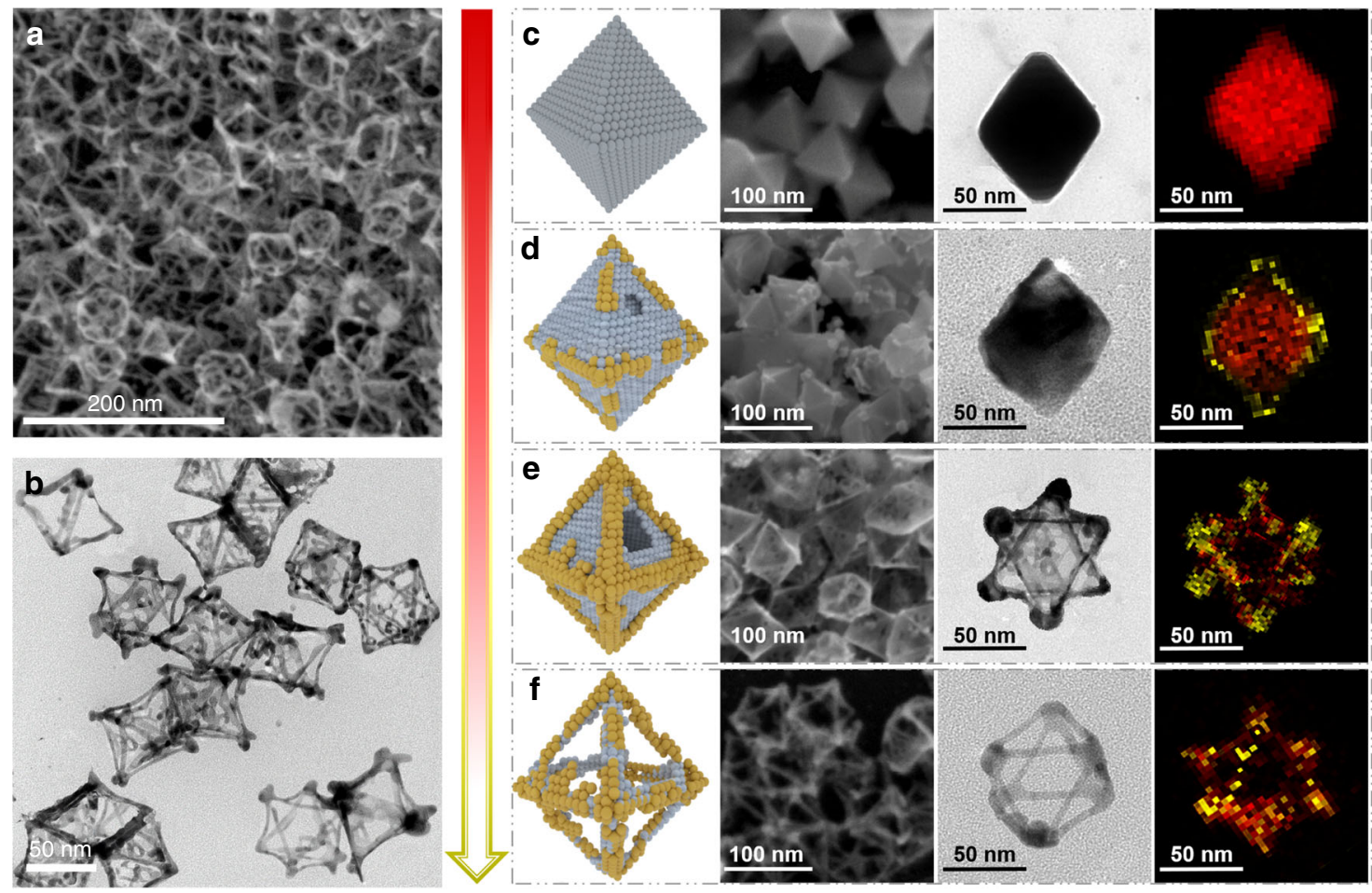

Fig. 1 Morphological evolution of $\mathrm{Ag}$ nanoparticles to $\mathrm{Au}_{3} \mathrm{Ag}$ nanoframes. a Scanning electron microscopy (SEM) and $\mathbf{b}$ transmission electron microscopy (TEM) overview of $\mathrm{Au}_{3} \mathrm{Ag}$ NFs showing high structural uniformity. The schematic diagram, SEM, TEM, and energy-dispersive X-ray (EDX) mapping images

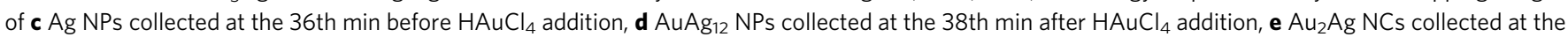
42th min, and $\mathbf{f} \mathrm{Au}_{3} \mathrm{Ag}$ NFs collected at the 46th min

retained in the soluble form by complexing with ODA and CTAB. In addition, the dissolution of $\mathrm{Ag}^{+}$ions promotes the local concentration of $\mathrm{Cl}^{-}$and $\mathrm{Br}^{-}$, further in favor of the pinhole growth via an autocatalytic process ${ }^{39}$. As the cavities inside the silver octahedra continuously grow, hollow Au-Ag cages with surface pinholes were formed as evidenced by both TEM and SEM images taken at the 42nd minute (Fig. 1e). Meanwhile, the edges of the $\mathrm{Au}-\mathrm{Ag}$ nanocages increased to $71.3 \pm 4.4 \mathrm{~nm}$ (Supplementary Fig. 1c).

Concurrent with the galvanic replacement reactions, the deposited $\mathrm{Au}$ and the underlying $\mathrm{Ag}$ atoms on the edges and vertices alloy with each other, driven by the high interdiffusion rate of $\mathrm{Au}$ and $\mathrm{Ag}$ at $125^{\circ} \mathrm{C}$ and the formation of energetically stabler alloyed phases. As the reaction continues, the inner Ag atoms are gradually etched away until the final collapse of the crystal surface, which is passivated from outside by ODA and halide ions. Instead, the edges and vertices of the nanocrystals are capable of surviving through the galvanic reactions, thanks to the stabilized $\mathrm{Au}-\mathrm{Ag}$ alloy layer. As a result, well-defined $\mathrm{Au}-\mathrm{Ag}$ nanoframes with ultrathin edges were obtained at the 46th min when the reaction was promptly stopped (Fig. 1f). The average size of the $\mathrm{Au}-\mathrm{Ag}$ nanoframes obtained from this stage is $71.8 \pm$ $4.1 \mathrm{~nm}$ (Supplementary Fig. 1d), similar to that of the nanocages from the third stage. We note that further extending the reaction time might lead to undesired structural damage through dealloying (Supplementary Fig. 4).

As an outcome of the above temporal study, bimetallic $\mathrm{Au}-\mathrm{Ag}$ nanostructures with morphologies of nanoparticles, nanocages and nanoframes can be obtained from the same one-pot reaction by terminating it at different stage. The atomic ratios of $\mathrm{Au}$ and $\mathrm{Ag}$ in each of these nanostructures were quantified by EDX, X-ray photoelectron spectroscopy (XPS), and inductively coupled plasma optical emission spectroscopy (ICP-OES), showing similar values to each other (Supplementary Table 1,
Supplementary Fig. 5). Specifically, the Au-Ag nanoparticles have an $\mathrm{Au} / \mathrm{Ag}$ ratio of approximately 1:12, whereas that of the nanocages is about 2:1 due to the removal of $\mathrm{Ag}$ atoms inside the nanoparticles. As for the $\mathrm{Au}-\mathrm{Ag}$ nanoframes, the atomic ratio of $\mathrm{Au} / \mathrm{Ag}$ is further increased to about 3:1 as a result of the loss of surface atoms. Consequently, based on the composition analysis, the $\mathrm{Au}-\mathrm{Ag}$ nanostructures obtained from different reaction stages are respectively designated as $\mathrm{Ag} \mathrm{NPs}, \mathrm{AuAg}_{12} \mathrm{NPs}$, $\mathrm{Au}_{2} \mathrm{Ag} \mathrm{NCs}$ and $\mathrm{Au}_{3} \mathrm{Ag} \mathrm{NFs}$, which will be used throughout the rest of discussions.

Lattice details of Au3Ag nanoframes. As the physiochemical properties of the alloyed nanoframes are highly correlated to their atomic arrangement and surface orientation, Cs-TEM was employed to characterize the detailed lattice configuration of $\mathrm{Au}_{3} \mathrm{Ag}$ NFs in high spatial resolution. Various sections chosen at the edges and vertices were elaborately inspected (Fig. 2, Supplementary Fig. 6). Figure 2a shows a thin edge of a nanoframe viewed from the (111) direction, expressing lattice fringes comprising the (100) and (110) planes. On its curved contours, the surfaces are full of zigzag atomic steps with the high-index facets denoted by different colors using the Microfacet notation developed by Somorjal et al. ${ }^{42,43}$. Beneath the surface, defects of edge dislocation, caused by the insertion of additional planes into the otherwise self-contained lattice, can be found as the one highlighted by the red dotted box shown in the upper inset of Fig. 2a. Further inside the edge dislocation, point defects of missing atoms are clearly discernable. The formation of edge dislocations further gives rise to lattice distortion, resulting in the development of low-angle tilt grain boundaries (yellow dotted box in Fig. 2a).

On the vertex of the nanoframe shown in Fig. 2b, a typical screw dislocation is present, probably resulted from local asymmetrical heating during $\mathrm{Au}$ deposition ${ }^{44}$. Upon intersecting 


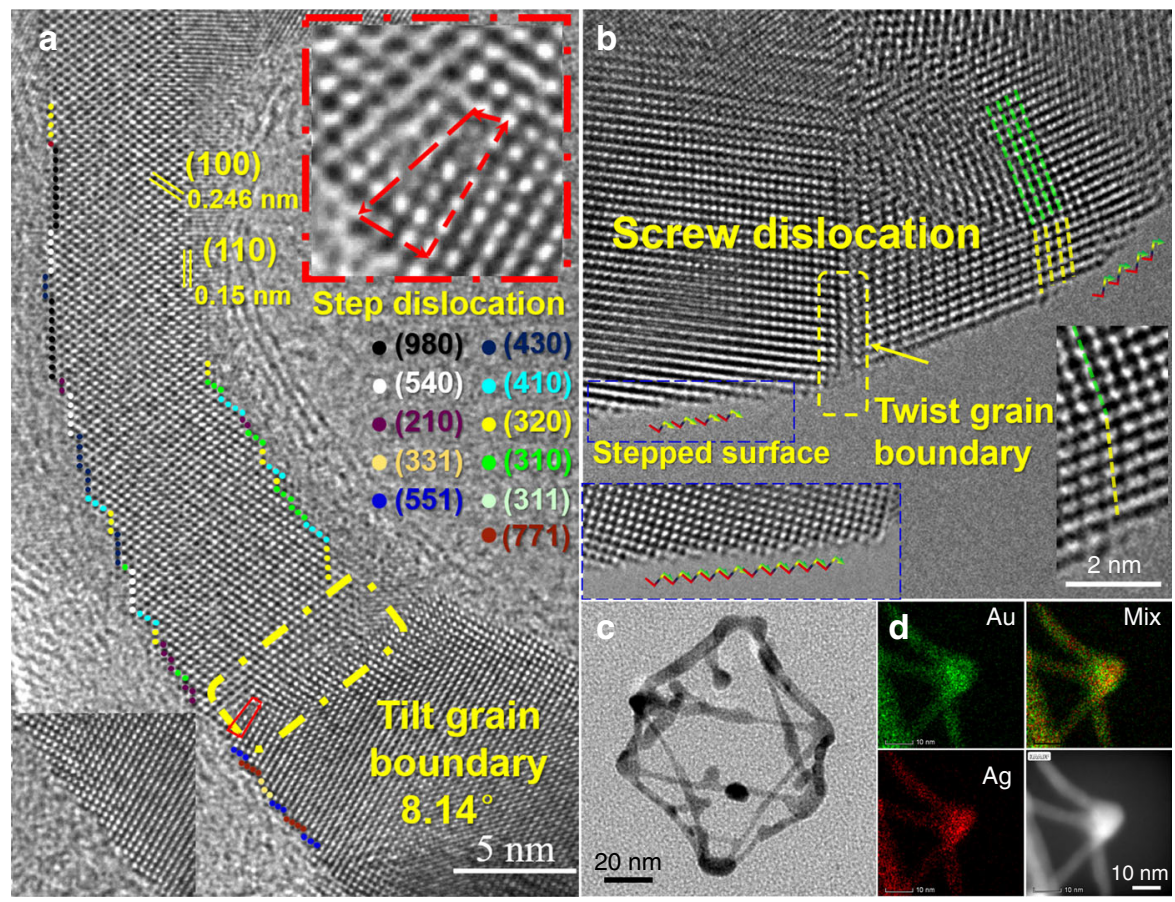

Fig. 2 Atomic structure of $\mathrm{Au}_{3} \mathrm{Ag}$ nanoframes revealing rich crystalline defects. a High-resolution lattice details on one of the edges displaying an edge dislocation, high-index surface atoms, point defects, and tilt grain boundaries. $\mathbf{b}$ High-resolution lattice details on one of the vertices displaying stepped surface atoms, screw dislocations, and twist grain boundaries. c Transmission electron microscopy (TEM) overview of the nanoframe. $\mathbf{d}$ Energy-dispersive $\mathrm{X}$-ray (EDX) mapping images of $\mathrm{Au}$ and $\mathrm{Ag}$ on a vertex connecting four edges

with the crystal surface, the screw dislocation creates multiple step edges, propagating into self-perpetuating spirals. Stacking fault is another commonly observed defect with some in parallel with the $\mathrm{Au}$ (111) surface shown in Supplementary Fig. 6c. Besides, numerous grain boundaries are scattered throughout the vertices of the nanoframe. In general, the high-resolution analysis made here by CS-TEM unveiled abundant structural defects on the $\mathrm{Au}_{3} \mathrm{Ag} \mathrm{NFs}$, including atomic steps, dislocations, vacancies, and grain boundaries, which should effectively alter the surface electronic states, and thereby bring in dramatically different properties and activities from their bulk counterparts.

The high-resolution EDX mapping images acquired under the HAADF-STEM mode indicate on the Au-Ag NFs $\mathrm{Au}$ atoms are preferentially located atop the Ag core (Fig. 2d). By comparing the $\mathrm{Au}$ and $\mathrm{Ag}$ elemental mapping images (where a vertex connecting four edges is displayed), we note not only the intensity of the Au signal is higher, but also is the area it covers. This becomes even more obvious by overlaying the $\mathrm{Au}$ and $\mathrm{Ag}$ images together, affirming the surfaces are majorly constituted by $\mathrm{Au}$ atoms. It is well-known in order to minimize the overall Gibbs free energy, the inter-diffusion and segregation of alloyed elements can occur in most multi-component materials under suitable environmental bias, such as the high temperature synthetic conditions employed here. Therefore, the atomic inter-diffusion and thermal motion serve as the driving force for creating vacancies, steps and dislocations on the $\mathrm{Au}_{3} \mathrm{Ag}$ $\mathrm{NFs}^{45,46}$.

Spectroscopic analysis on structural and surface states. XRD analysis was carried out to characterize the evolution of crystallographic structure for the above $\mathrm{Au}-\mathrm{Ag}$ nanostructures collected from different reaction stages (Fig. 3a, b). Since Au and Ag have very similar face-centered cubic (fcc) crystal structure, their four main diffraction peaks indexed to the (111), (200), (220), and (311) planes are very close to each other. However, a careful examination will find out there still exist subtle differences between $\mathrm{Au}$ and $\mathrm{Ag}$ in the peak positions of (111) and (200) planes $\left(2 \theta_{\mathrm{Au}(111)}=38.10^{\circ}\right.$ vs. $2 \theta_{\mathrm{Ag}(111)}=37.93^{\circ}, 2 \theta_{\mathrm{Au}(200)}=$ $44.37^{\circ}$ vs. $\left.2 \theta_{\mathrm{Au}}(200)=44.142^{\circ}\right)$. As shown in Fig. $3 \mathrm{a}$, XRD patterns of the four samples collected at the 36th, 38th, 42nd, and 46th min of the reaction, namely $\mathrm{Ag} \mathrm{NPs}, \mathrm{AuAg}_{12} \mathrm{NPs}, \mathrm{Au}_{2} \mathrm{Ag}$ $\mathrm{NCs}$, and $\mathrm{Au}_{3} \mathrm{Ag} \mathrm{NFs}$, present decreased crystallinity with increasing reaction time, which is in accordance with the alloying process. A closer inspection on the (111) and (200) peaks clearly reveals their shift to higher $2 \theta$ angles as the Au content increases in the nanostructures (Fig. 3b), corroborating the above elemental analysis by EDX, XPS, and ICP-OES.

To probe the surface electronic states and local coordination of $\mathrm{Au}$ and $\mathrm{Ag}$ atoms, XPS and X-ray absorption fine structure (XAFS) analyses were performed on the samples of $\mathrm{AuAg}_{12} \mathrm{NPs}$, $\mathrm{Au}_{2} \mathrm{Ag}$ NCs, and $\mathrm{Au}_{3} \mathrm{Ag}$ NFs. As shown in Fig. 3c, the XPS $\mathrm{Au} 4 \mathrm{f}$ peaks shift to higher binding energies as the $\mathrm{Au}-\mathrm{Ag}$ nanostructures transform from nanoparticles to nanocages and further to nanoframes, with a total displacement of $0.5 \mathrm{eV}$. This upshift of binding energies indicates that in comparison to $\mathrm{Au}_{2} \mathrm{Ag} \mathrm{NCs}$ and $\mathrm{AuAg}_{12} \mathrm{NPs}$, the Au d orbitals of $\mathrm{Au}_{3} \mathrm{Ag}$ NFs are more depleted since the binding-energy shift strongly correlates to the Coulomb integrals of $F_{4 \mathrm{f}, 5 \mathrm{~d}}{ }^{47,48}$. On the other side, the $\mathrm{Ag} 3 \mathrm{~d}$ peaks shift slightly to lower binding energies with a total displacement of $0.3 \mathrm{eV}$ from $\mathrm{AuAg}_{12} \mathrm{NPs}$ to $\mathrm{Au}_{3} \mathrm{Ag}$ NFs (Fig. 3d). These observations suggest that $\mathrm{Au}$ in the $\mathrm{Au}_{3} \mathrm{Ag}$ NFs are positively polarized $\left(\mathrm{Au}^{\delta+}\right)$ and their d-band center shifts up toward the Fermi level $\left(E_{\mathrm{F}}\right)$, whereas the $\mathrm{Ag} \mathrm{d}$ bands shift down relative to $E_{\mathrm{F}}{ }^{49-51}$. Interestingly, this observation is opposite to the charge transfer between $\mathrm{Au}$ and $\mathrm{Ag}$ induced by the ligand effect in respond to the higher work function of $\mathrm{Au}$, inferring that compared to the structural attributes the ligand effect is negligible here. To further resolve this inconsistency, all samples were then subjected to analyses of the $\mathrm{Au} \mathrm{L}_{3}$-edge X-ray absorption nearedge structure (XANES). 


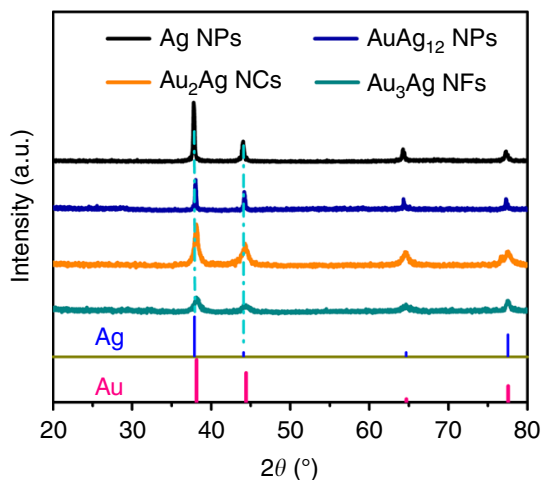

C

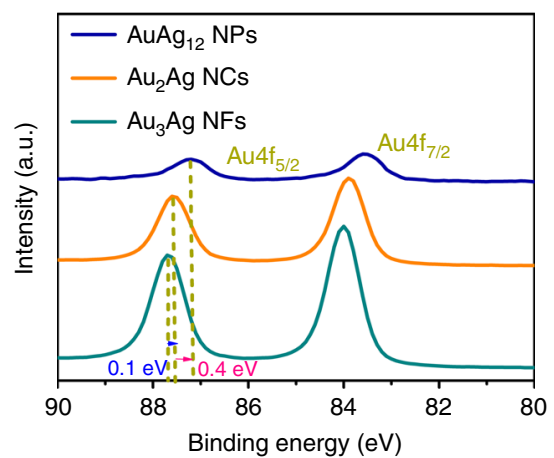

e

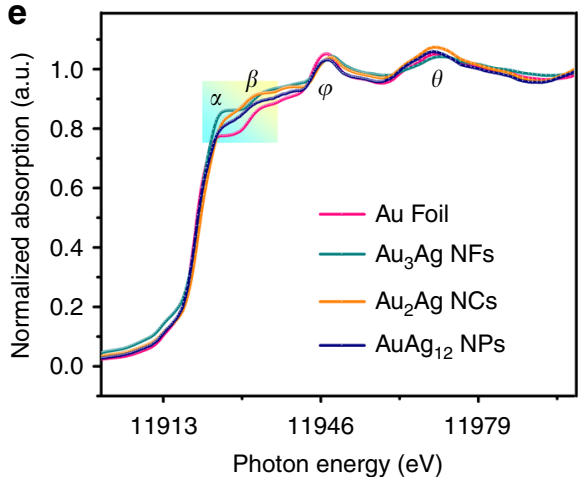

b

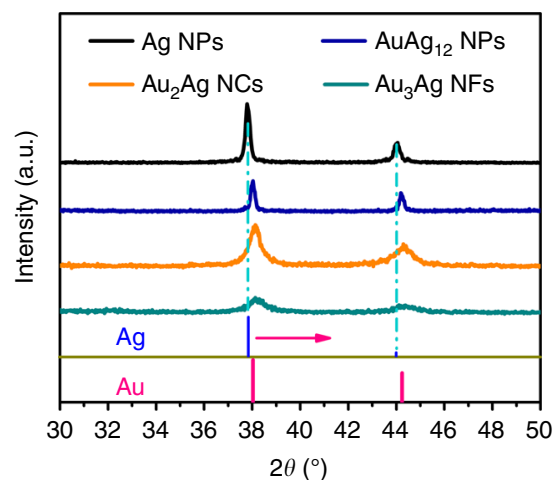

d
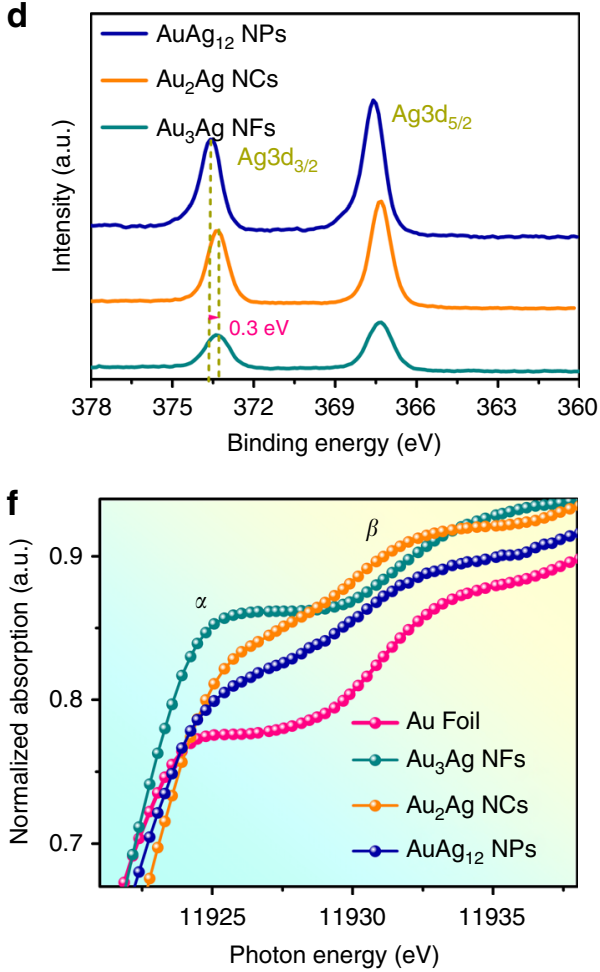

Fig. 3 Spectroscopy analysis on the structural evolution for all AuAg nanostructures. a X-ray diffraction (XRD) and $\mathbf{b}$ zoom-in spectra of Ag NPs, $\mathrm{AuAg}_{12} \mathrm{NPs}, \mathrm{Au}_{2} \mathrm{Ag} \mathrm{NCs}$, and $\mathrm{Au}_{3} \mathrm{Ag} \mathrm{NFs}$. $\mathbf{X}$-ray photoelectron spectroscopy (XPS) Au $4 \mathrm{f}$ and $\mathbf{d} \mathrm{Ag} 3 \mathrm{~d}$ spectra of $\mathrm{AuAg}_{12} \mathrm{NPs}, \mathrm{Au}_{2} \mathrm{Ag} \mathrm{NCs}$, and $A u_{3} \mathrm{Ag}$ NFs. e X-ray absorption near-edge structure (XANES), and $\mathbf{f}$ zoom-in spectra obtained from the $A u L_{3}$-edge absorption of $\mathrm{AuAg}_{12} \mathrm{NPs}, \mathrm{Au}_{2} \mathrm{Ag} \mathrm{NCs}$, and $\mathrm{Au}_{3} \mathrm{Ag} \mathrm{NFs}$ in comparison to the gold foil

Figure 3e shows that all $\mathrm{Au}-\mathrm{Ag}$ nanostructures display similar resonance patterns in the normalized XANES spectra as that of the Au foil with four characteristic peaks, indicating they all have Au-like coordination environments. Importantly, the leftmost adsorption peak (peak $\alpha$ ) refers to the intensity of resonance at the threshold (white-line peak) associated with the dipole transition from $2 \mathrm{p}_{3 / 2}$ to $5 \mathrm{~d}_{5 / 2,3 / 2}$, reflecting the unoccupied density of $d$ states at the Fermi level. As magnified in Fig. 3f, the white-line peak intensity follows the order of $\mathrm{Au}$ foil $<$ $\mathrm{AuAg}_{12} \mathrm{NPs}_{2}<\mathrm{Au}_{2} \mathrm{Ag} \mathrm{NCs}<\mathrm{Au}_{3} \mathrm{Ag} \mathrm{NFs}$, suggesting a corresponding increase in $\mathrm{d}$ orbital depletion, which is in good agreement with the above XPS results. Previous studies have shown the ligand effect has negligible impact on the surface reactivity beyond a few atomic layers ${ }^{52,53}$, it is therefore, surmised the surface structure, lattice distortion and defects play a dominating role in increasing the observed d-hole population of $\mathrm{Au}$. Furthermore, both the FT-EXAFS of the Au foil and $\mathrm{Au}_{3} \mathrm{Ag}$ NFs display doublets in the region of 1.8-3.4 $\AA$, comprising a low$\mathrm{R}$ peak $(2.0-2.2 \AA)$ and a high- $\mathrm{R}$ peak $(2.4-2.9 \AA)$ that can be ascribed to the nearest $\mathrm{Au}-\mathrm{Au}$ bonding (Supplementary Fig. 7) 54,55. This enables us to further deduce quantitative structural parameters shown in Supplementary Table 2 regarding the local $\mathrm{Au}$ bonding environment in $\mathrm{Au}$ foil and $\mathrm{Au}_{3} \mathrm{Ag}$ NFs. Compared to the bulk $\mathrm{Au}$ foil, $\mathrm{Au}_{3} \mathrm{Ag}$ NFs exhibit significant reduction in the coordination number of nearest $\mathrm{Au}$ neighbors from 12 to 9.4, confirming most $\mathrm{Au}$ atoms in $\mathrm{Au}_{3} \mathrm{Ag}$ NFs are in surface or defect states. Further analysis on the resulted bond lengths suggests a lattice contraction in the $\mathrm{Au}_{3} \mathrm{Ag} \mathrm{NFs}(2.86 \AA$ for Au foil vs. $2.84 \AA$ for $\mathrm{Au}_{3} \mathrm{Ag} \mathrm{NFs}$ ), owing again to the existence of abundant defects in the alloyed structure. This argument is further evidenced by the relatively large Debye-Waller factor $\left(\sigma^{2}\right)$ obtained for $\mathrm{Au}_{3} \mathrm{Ag}$ $\mathrm{NFs}$, corroborating the increased disorder in the $\mathrm{Au}-\mathrm{Au}$ shell as a result of the defective lattice structure, echoing previous observations made by Cs-TEM.

Complementary to the above spectroscopy analyses, cyclic voltammetry $(\mathrm{CV})$ was taken to further correlate the microstructure with surface redox potentials for $\mathrm{Au}_{3} \mathrm{Ag} \mathrm{NFs}, \mathrm{Au}_{2} \mathrm{Ag}$ 
NCs, and $\mathrm{AuAg}_{12}$ NPs. All CVs acquired in $0.1 \mathrm{M} \mathrm{HClO}_{4}$ exhibit two major anodic peaks, attributed to the oxidation of surface $\mathrm{Ag}$ and $\mathrm{Au}$ atoms, respectively (Supplementary Fig. 8). The sample of $\mathrm{Au}_{3} \mathrm{Ag} \mathrm{NFs}$ exhibits the largest $\mathrm{Au}$ oxidation peak located at $1.43 \mathrm{~V}$ (vs. RHE), lower than those of $\mathrm{Au}_{2} \mathrm{Ag} \mathrm{NCs}(1.59 \mathrm{~V})$ and $\mathrm{AuAg}_{12} \mathrm{NPs}(1.80 \mathrm{~V})$. It also shows a smaller Ag oxidation peak at the lowest potential $(0.56 \mathrm{~V})$ with respect to $\mathrm{Au}_{2} \mathrm{Ag} \mathrm{NCs}$ $(0.58 \mathrm{~V})$ and $\mathrm{AuAg}_{12} \mathrm{NPs}(0.68 \mathrm{~V})$, corroborating that $\mathrm{Au}_{3} \mathrm{Ag}$ NFs possess more unsaturated and active surface atoms that are easier to oxidize, in good agreement with the EXAFS results.

Structure-dependent MOR performance. The electrocatalytic activities of $\mathrm{Au}_{3} \mathrm{Ag} \mathrm{NFs}, \mathrm{Au}_{2} \mathrm{Ag} \mathrm{NCs}$, and $\mathrm{AuAg}_{12}$ NPs toward MOR were evaluated against the benchmark of commercial $20 \%$ $\mathrm{Pt} / \mathrm{C}$. Figure $4 \mathrm{a}$ shows the CVs of all tested samples in $\mathrm{N}_{2}$-purged $0.5 \mathrm{M} \mathrm{KOH}$ solution with $2 \mathrm{M}$ methanol, exhibiting characteristic MOR behaviors with both forward and backward oxidation peaks. For $\mathrm{Au}_{3} \mathrm{Ag} \mathrm{NFs}$, the forward scan reveals a MOR onset potential at $0.30 \mathrm{~V}$ and peak oxidation current at $0.92 \mathrm{~V}$. In the backward sweep, a second oxidation peak is observed at $0.65 \mathrm{~V}$, owing to the removal of residual carbonaceous species formed in the forward $\operatorname{scan}^{56}$. For comparison, the commercial Pt/C exhibits a higher onset potential at $0.4 \mathrm{~V}$ but lower potential of peak current at $0.78 \mathrm{~V}$. Nevertheless, the peak current density of $\mathrm{Pt} / \mathrm{C}$ (591.9 mA mg $\left.{ }_{\mathrm{pt}}{ }^{-1} @ 0.78 \mathrm{~V}\right)$ is still lower than the current density of $\mathrm{Au}_{3} \mathrm{Ag}$ NFs at the same potential $\left(814.5 \mathrm{~mA} \mathrm{mg}{ }_{\mathrm{Au}}{ }^{-1} @ 0.78 \mathrm{~V}\right)$, not to mention its peak current density of $950 \mathrm{~mA} \mathrm{mg}_{\mathrm{Au}}{ }^{-1} @ 0.92 \mathrm{~V}$. By contrast, $\mathrm{Au}_{2} \mathrm{Ag} \mathrm{NCs}$ and $\mathrm{AuAg}_{12}$ NPs present much higher peak-current potentials at 1.15 and $1.21 \mathrm{~V}$, respectively, with the corresponding peak current densities of 141.4 and $20.9 \mathrm{~mA} \mathrm{mg}_{\mathrm{Au}}{ }^{-1}$. Consequently, the mass activity (MA) of $\mathrm{Au}_{3} \mathrm{Ag}$ NFs is 1.6, 6.7, and 45.5 times that of commercial Pt/C, $\mathrm{Au}_{2} \mathrm{Ag}$ $\mathrm{NCs}$, and $\mathrm{AuAg}_{12}$ NPs, respectively. After normalized to the specific surface area (quantified by CO stripping in Supplementary
Fig. 9), the SA of $\mathrm{Au}_{3} \mathrm{Ag} \mathrm{NFs}$ is $3.38 \mathrm{~mA} \mathrm{~cm}^{-2}$, which is $3.9,4.6$, and 8.0 times that of the commercial $\mathrm{Pt} / \mathrm{C}, \mathrm{Au}_{2} \mathrm{Ag} \mathrm{NCs}$, and $\mathrm{AuAg}_{12}$ NPs, respectively (Fig. 4b). In addition, the catalytic MOR performance of the octahedral Ag NPs obtained at the 36th min before the addition of $\mathrm{HAuCl}_{4}$ was also examined, and the results show no obvious difference between the CV curves obtained with and without methanol (Supplementary Fig. 10), suggesting that the $\mathrm{Au}$ phase in the bimetallic nanostructures plays a dominant role in catalyzing the methanol oxidation.

To confirm the observed high catalytic activities are indeed due to the oxidation of methanol, rather than any residual organics, we performed concentration-dependent studies on the $\mathrm{Au}_{3} \mathrm{Ag}$ NFs catalyst by varying the concentration of methanol in $0.5 \mathrm{M}$ $\mathrm{KOH}$ (Supplementary Fig. 11). The measured current increases with the methanol addition until a concentration of $2 \mathrm{M}$, beyond which the MOR kinetics start to decrease. This observation strongly suggests a trade-off between the reactant concentration and the permittivity of the electrolyte exerting on the reaction rate. Therefore, the optimal methanol concentration of $2 \mathrm{M}$ was used throughout this work. What's more, CVs acquired at different scan rates on $\mathrm{Au}_{3} \mathrm{Ag} \mathrm{NFs}$ show that the anodic peak current is linearly proportional to the square root of scan rate, indicating the electrocatalytic oxidation of methanol is governed by a diffusion-controlled process (Fig. 4c), which is greatly facilitated by the highly exposed active sites of $\mathrm{Au}_{3} \mathrm{Ag}$ NFs. To further identify the activity origin, we deliberately destroy the framework of the nanoframes through ball milling, and found out the MOR MA declined only slightly from 950 to $914 \mathrm{~mA}$ $\mathrm{mg}_{(\mathrm{Au})}{ }^{-1}$ at similar voltages (Supplementary Fig. 12). CS-TEM images indicate after ball milling the crystalline defects were mostly unaffected (Supplementary Fig. 13), but the frameworks were turned into thin wires (Supplementary Fig. 14). This offers extra evidence to support the enhanced MOR activity is indeed majorly originated from the abundant crystalline defects.
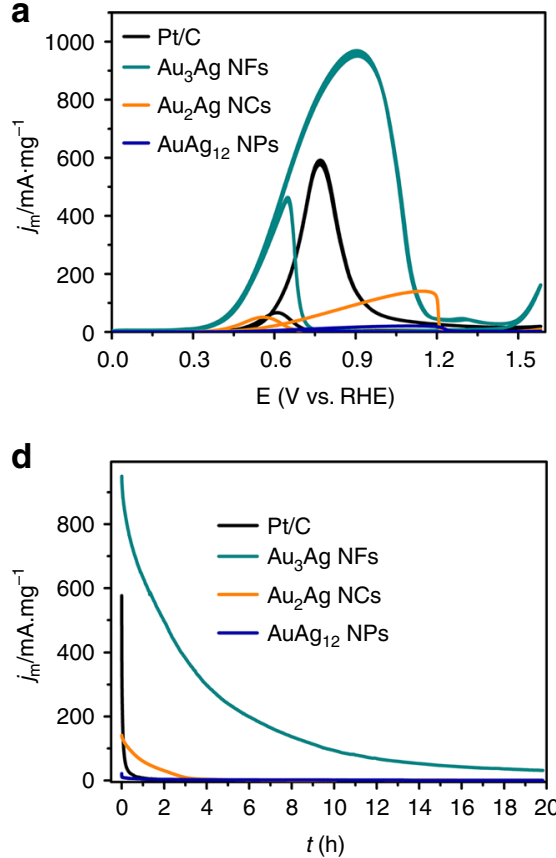
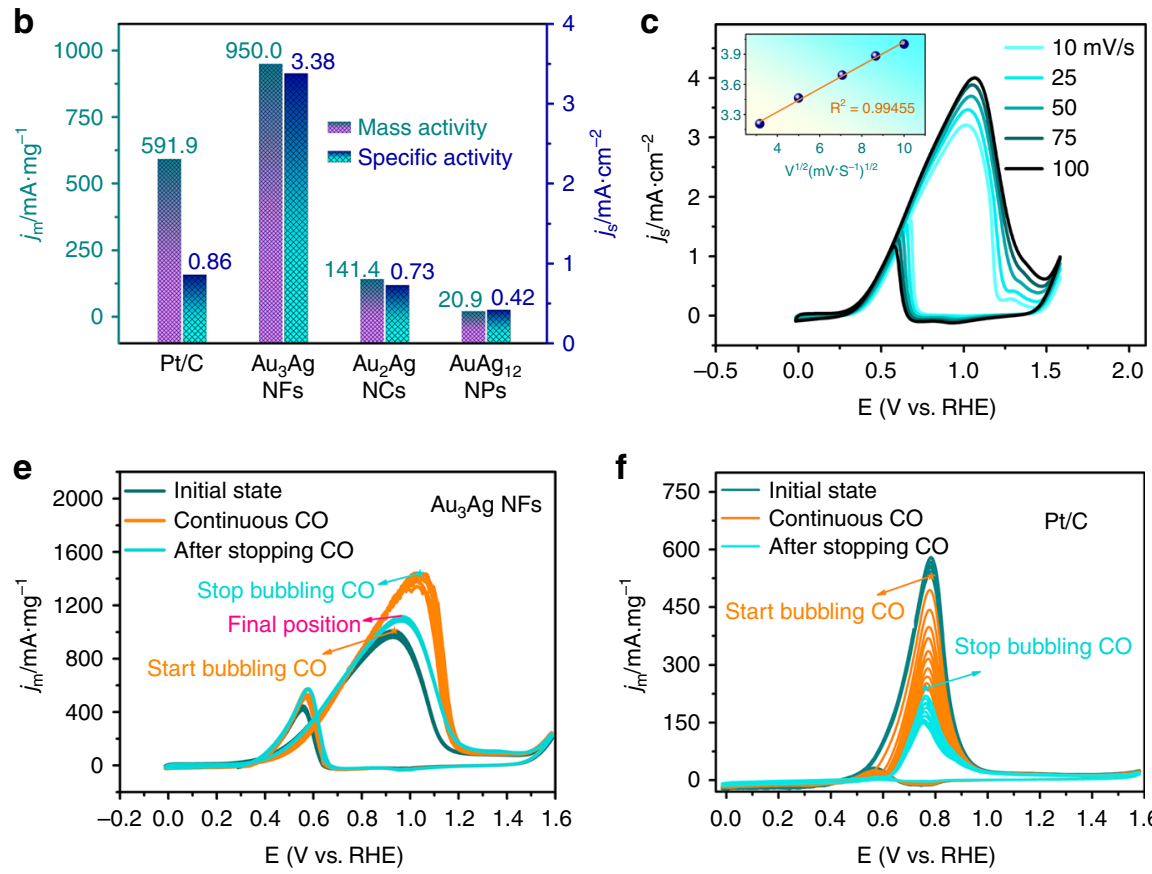

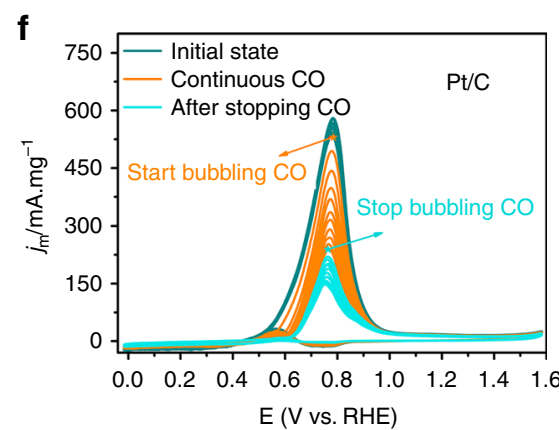

Fig. 4 Electrocatalytic performances of $\mathrm{Au}-\mathrm{Ag}$ nanostructures. a Cyclic Voltammetry (CV) curves taken at a sweep rate of $20 \mathrm{mV} \mathrm{s} \mathrm{s}^{-1}$ for all examined catalysts. b The corresponding histogram of mass and specific activities. $\mathbf{c} C V s$ of $A u_{3} A g$ NFs taken at various scan rates. The inset shows a linear response of current density with respect to the square root of scan rates. $\mathbf{d}$ Chronoamperometric $i-t$ curves of all examined catalysts up to $20 \mathrm{~h}$. e Evolution of $\mathrm{CV}$ curves for $\mathrm{Au}_{3} \mathrm{Ag}$ NFs with the $\mathrm{CO}$ supply turned on and off for a continuous 10 cycles. $\mathbf{f}$ Evolution of $\mathrm{CV}$ curves for Pt/C with the $\mathrm{CO}$ supply turned on and off for a continuous 10 cycles. The methanol oxidation reactions were performed in deoxygenated solutions of $2 \mathrm{M} \mathrm{CH} \mathrm{H}_{3} \mathrm{OH}$ and $0.5 \mathrm{M} \mathrm{KOH}$ 
To assess the catalytic stability, chronoamperometric $i-t$ curves were taken for all $\mathrm{Au}-\mathrm{Ag}$ nanostructures, in comparison with the commercial $\mathrm{Pt} / \mathrm{C}$, at their peak-current potentials (Fig. 4d). The $\mathrm{Au}_{3} \mathrm{Ag}$ NFs exhibited a gradual decrease in mass activity, retaining $502.1 \mathrm{~mA} \mathrm{mg}^{-1}$ after $2 \mathrm{~h}$ and $32.2 \mathrm{~mA} \mathrm{mg}^{-1}$ after $20 \mathrm{~h}$. By contrast, the $\mathrm{Au}_{2} \mathrm{Ag} \mathrm{NCs}$ and $\mathrm{AuAg}_{12}$ NPs showed a much faster activity decay, with only 34.2 and $3.2 \mathrm{~mA} \mathrm{mg}^{-1}$ retained after $2 \mathrm{~h}$, respectively. As for the Pt/C, the mass activity was quickly lost and almost diminished to $0 \mathrm{~mA} \mathrm{mg}^{-1}$ after just $1 \mathrm{~h}$, likely due to the heavy accumulation of carbonaceous intermediates poisoning the active sites on catalyst surface. This point of view can be further understood from the comparison of $\mathrm{I}_{\mathrm{f}} / \mathrm{I}_{\mathrm{b}}$, the ratio of the forward anodic peak current $\left(I_{\mathrm{f}}\right)$ to the backward anodic peak current $\left(I_{\mathrm{b}}\right)$, which is used to assess the tolerance of the catalyst to the poisoning carbonaceous intermediates such as carbon monoxide and formate. A lower $I_{\mathrm{f}} / I_{\mathrm{b}}$ value signifies the capability of the catalyst to eliminate residual carbonaceous species from surface, whereas a high $I_{\mathrm{f}} / I_{\mathrm{b}}$ value suggests its incompetence on this matter ${ }^{27}$. Specifically, the $\mathrm{Au}_{3} \mathrm{Ag}$ NFs has the lowest $I_{\mathrm{f}} / I_{\mathrm{b}}$ of 2.5 , in comparison to 9.2, 2.9, and 5.6 for the commercial $\mathrm{Pt} / \mathrm{C}, \mathrm{Au}_{2} \mathrm{Ag} \mathrm{NCs}$, and $\mathrm{AuAg}_{12} \mathrm{NPs}$, respectively. As a result, among all tested catalysts the $\mathrm{Au}_{3} \mathrm{Ag} \mathrm{NFs}$ demonstrated the best catalytic stability of MOR.

Further to meet the requirements for practical fuel cell applications, all catalysts were cycled between 0 and $1.6 \mathrm{~V}$ at a sweeping rate of $20 \mathrm{mVs}^{-1}$ in $2 \mathrm{M}$ methanol and $0.5 \mathrm{M} \mathrm{KOH}$ for a duration of 500 cycles to evaluate the long-term MOR performance (Supplementary Fig. 15). The mass activities of the $\mathrm{Au}_{3} \mathrm{Ag}$ NFs and $\mathrm{Au}_{2} \mathrm{Ag} \mathrm{NCs}$, respectively increased from 894.5 to $950.0 \mathrm{~mA} \mathrm{mg}^{-1}$ and 136.1 to $141.4 \mathrm{~mA} \mathrm{mg}^{-1}$ after 50 cycles, reflecting an initial activation process. After 100 cycles, the corresponding MA values dropped to 79 and $72 \%$, and further to 12 and $15 \%$ after 300 cycles. By contrast, the mass activity of the commercial Pt/C decreased substantially from 590.9 to $271.1 \mathrm{~mA}$ $\mathrm{mg}^{-1}$ (54\% loss) after only 50 cycles, and further to $58.4 \mathrm{~mA} \mathrm{mg}^{-1}$ (90\% loss) after 100 cycles. As for the $\mathrm{AuAg}_{12}$ NPs, The MOR performance is very poor with a negligible current density after 300 cycles. Noteworthy, there was no apparent change in the structure of $\mathrm{Au}_{3} \mathrm{Ag} \mathrm{NFs}$ after the first 100 cycles, but some fractured and conglobated species start to occur after the extended 500 cycles (Supplementary Fig. 16). More importantly, the initial stepped surfaces tend to be flattened out showing less defect sites due to the rearrangement of surface atoms, which might account for the observed decay in MOR performance (Supplementary Fig. 17). Collectively, the above CV and chronoamperometry tests clearly demonstrate the superior MOR activity and stability of $\mathrm{Au}_{3} \mathrm{Ag}$ NFs against $\mathrm{Au}_{2} \mathrm{Ag} \mathrm{NCs}$ and $\mathrm{AuAg}_{12} \mathrm{NPs}$, as well as the commercial Pt/C.

CO-promoted MOR activities. Given that CO poisoning is one of the vital issues in devastating the MOR stability, both $\mathrm{CO}$ stripping and purging experiments were carried out to interrogate the impact of $\mathrm{CO}$ adsorption on the catalytic behavior of all catalysts. Supplementary Fig. 9 shows the CO stripping curves of all $\mathrm{Au}-\mathrm{Ag}$ nanostructures in $0.1 \mathrm{M} \mathrm{HClO}_{4}$, where both the $\mathrm{CO}$ oxidation potentials of $\mathrm{Au}_{3} \mathrm{Ag} \mathrm{NFs}$ and $\mathrm{Au}_{2} \mathrm{Ag} \mathrm{NCs}$ at 0.59 and $0.73 \mathrm{~V}$ are far below their MOR peak-current potentials at 0.92 and $1.15 \mathrm{~V}$, respectively. No much difference between the CV curves before and after $\mathrm{CO}$ stripping was observed for $\mathrm{AuAg}_{12}$ $\mathrm{NPs}$, indicating $\mathrm{Au}$ are the main $\mathrm{CO}$ absorption site. The shoulder peak at $0.5 \mathrm{~V}$ overlapped with $\mathrm{CO}$ oxidation on $\mathrm{Au}_{3} \mathrm{Ag}$ NFs and diminished after $\mathrm{CO}$ stripping is likely due to the COinduced $\mathrm{OH}^{-}$adsorption on $\mathrm{Au}^{34}$. By contrast, $\mathrm{Pt} / \mathrm{C}$ exhibits a $\mathrm{CO}$ oxidation peak at $0.92 \mathrm{~V}$, much higher than its methanol oxidation potential at $0.78 \mathrm{~V}$ (Supplementary Fig. 9d). This result provides direct evidence for the poor MOR stability of $\mathrm{Pt} / \mathrm{C}$ by $\mathrm{CO}$ poisoning, corroborating the previous $I_{\mathrm{f}} / I_{\mathrm{b}}$ comparison. Furthermore, by integrating the area of CO stripping and subtracting the area of $\mathrm{Ag}$ oxidation, the electroactive surface area can be obtained for $\mathrm{Au}_{3} \mathrm{Ag} \mathrm{NFs}, \mathrm{Au}_{2} \mathrm{Ag} \mathrm{NCs}, \mathrm{AuAg}_{12} \mathrm{NPs}$, and $\mathrm{Pt} / \mathrm{C}$ being 27.8, 19.2, 4.9, and $68.89 \mathrm{~m}^{2} \mathrm{~g}^{-1}$, respectively. These values were used in calculating the specific activities due to the similar oxidation nature of MOR and CO stripping.

$\mathrm{CO}$ was purged into the electrolyte containing $2 \mathrm{M}$ methanol to examine the evolution of MOR kinetics on the catalysts (Fig. 4e, f). Surprisingly, upon $\mathrm{CO}$ bubbling the peak current density of MOR on $\mathrm{Au}_{3} \mathrm{Ag}$ NFs increased abruptly from 950.0 to $1339.8 \mathrm{~mA} \mathrm{mg}^{-1}$, followed by further gradual increment to $1438.6 \mathrm{~mA} \mathrm{mg}^{-1}$ in the next 10 cycles. After cutting off the CO supply, the peak current density dropped back to $1113.5 \mathrm{~mA} \mathrm{mg}^{-1}$ by the end of subsequent 10 cycles, but still higher than the original value without $\mathrm{CO}$ purge (Fig. 4e). As a comparison, the peak current of MOR catalyzed by $\mathrm{Pt} / \mathrm{C}$ decreased from 530.1 to $239.4 \mathrm{~mA} \mathrm{mg}^{-1}$ after purging $\mathrm{CO}$ for $10 \mathrm{CV}$ cycles, and kept declining even when $\mathrm{CO}$ was shut off (Fig. 4f). This set of experiments clearly illustrate while $\mathrm{CO}$ is poisonous for $\mathrm{Pt}$, it actually promotes the MOR on $\mathrm{Au}_{3} \mathrm{Ag}$ NFs. Similar COpromoting behavior on the Au (111) surface was also observed by Rodriguez et al., who attributed the enhanced reactivity to the enhancement in electrostatic $\mathrm{OH}^{-}$bonding, as a result of the change in electrostatic surface potential (work function) when $\mathrm{CO}$ is adsorbed atop the gold surface ${ }^{34,57,58}$. We note that these observations are conceptually analogous to the homogeneous electrocatalysis catalyzed by organometallics, of which the catalytic properties of the active metal center can be tuned by tailoring its coordination with organic ligands, such as the Monsanto and Cativa processes using $\mathrm{CO}$ as the ligand ${ }^{59,60}$. In our case of $\mathrm{Au}_{3} \mathrm{Ag} \mathrm{NF}$ we also surmise the adsorption of $\mathrm{CO}$ promotes the anionic $\mathrm{OH}^{-}$ binding to the alloyed surface, which in turn effectively catalyzes the deprotonation of methanol. This argument is further supported by the lowered potentials of $\mathrm{OH}^{-}$adsorption and $\mathrm{Au}$ oxidation when comparing the $\mathrm{Au}_{3} \mathrm{Ag}$ NFs with other catalysts in $\mathrm{CV}$ measurements under alkaline conditions (Supplementary Fig. 18).

To further elucidate the defect-mediated activity enhancement on $\mathrm{Au}_{3} \mathrm{Ag}$ NFs and the CO-promoting effect, we applied the firstprinciples method in conjunction with the computational hydrogen electrode model to investigate the reaction free energy and activation barrier of all elementary steps along the reaction coordinate (see Supporting information for calculation details). As the structure of $\mathrm{Au}_{3} \mathrm{Ag} \mathrm{NFs}$ is highly complex comprising a myriad of defects, in view of a reasonable computational cost we mainly considered two of the most abundant defect types representing the highly unsaturated surface, namely the highindex facets and atomic vacancies. Figure $5 \mathrm{a}$ and Supplementary Fig. 19a illustrate the constructed $\mathrm{Au}_{3} \mathrm{Ag}$ (410) and $\mathrm{Au}_{3} \mathrm{Ag}-\mathrm{Au}_{\mathrm{vac}}$ surface models, in comparison to the $\mathrm{Au}_{3} \mathrm{Ag}$ (111), $\mathrm{Au}$ (111), and $\mathrm{Pt}$ (111) references. The methanol adsorption on these surfaces takes similar configuration with the $\mathrm{CH}_{3} \mathrm{OH}$ molecule residing atop the $\mathrm{Au}(\mathrm{Pt})$ atom via the $\mathrm{O}$ bonding (Supplementary Fig. 20). Notably, the surfaces of $\mathrm{Au}_{3} \mathrm{Ag}$ (410) and $\mathrm{Au}_{3} \mathrm{Ag}-\mathrm{Au}_{\mathrm{vac}}$ possess more negative adsorption energies $(-0.18$ and $-0.13 \mathrm{eV}$, respectively) than those of the $\mathrm{Au}_{3} \mathrm{Ag}(111)(-0.09 \mathrm{eV}), \mathrm{Au}$ (111) $(-0.10 \mathrm{eV})$, and Pt (111) $(-0.05 \mathrm{eV})$, implying the defectmediated high-methanol affinity of the $\mathrm{Au}_{3} \mathrm{Ag}$ NFs surfaces (Supplementary Table 3).

Then, on the surfaces of $\mathrm{Au}_{3} \mathrm{Ag}$ (410), $\mathrm{Au}_{3} \mathrm{Ag}-\mathrm{Au}_{\mathrm{vac}}, \mathrm{Au}_{3} \mathrm{Ag}$ (111), Au (111), and Pt (111) all possible elementary steps of MOR were considered involving both deprotonation and hydroxyl addition. The various routes of reaction cascade are shown in Supplementary Fig. 21 and the optimized intermediates are displayed in Supplementary Fig. 20. The $\mathrm{Au}_{3} \mathrm{Ag}$ (111) and $\mathrm{Au}$ 


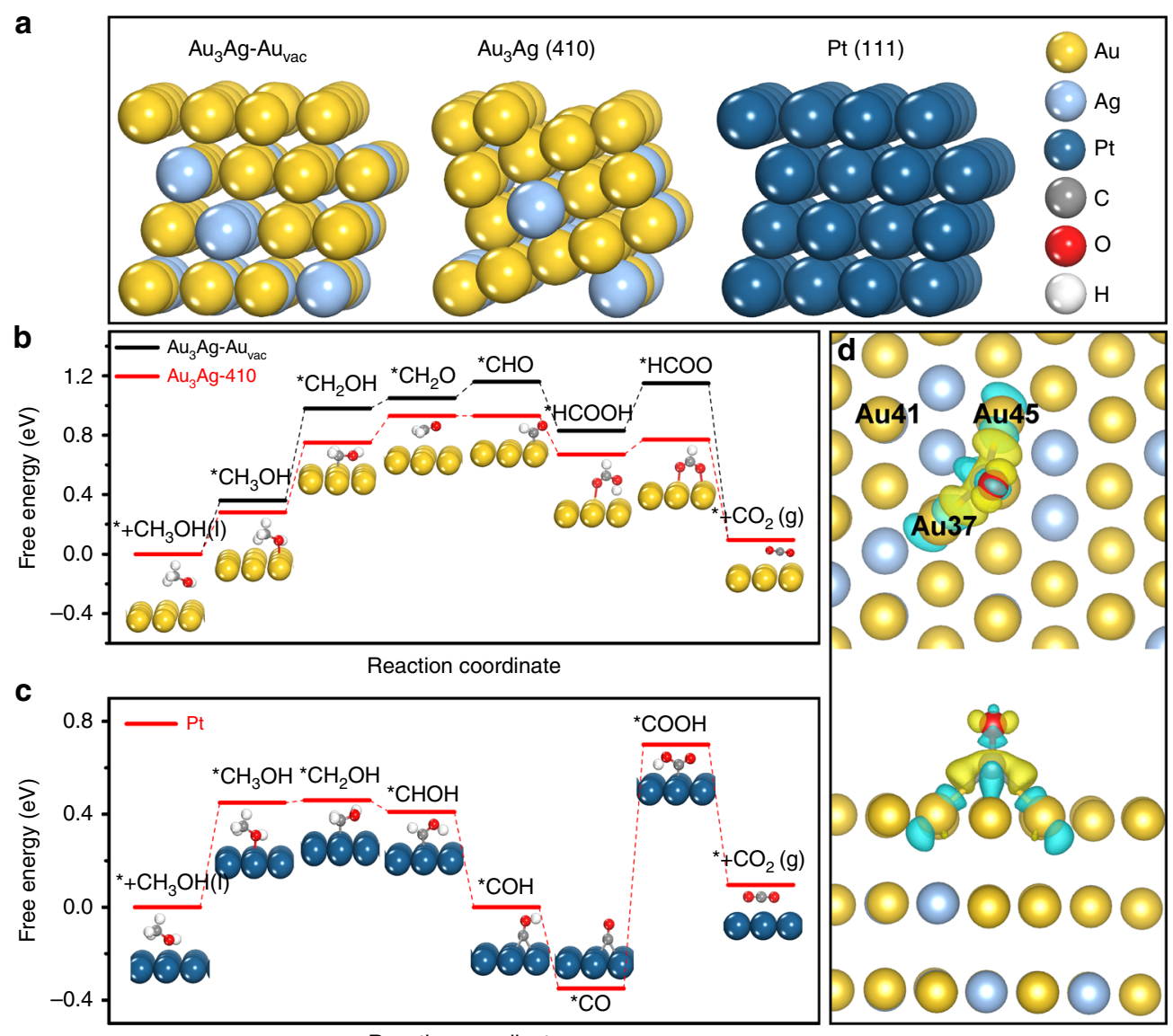

Reaction coordinate

Fig. 5 Simulated methanol oxidation mechanisms on the catalyst surfaces. a Stable configuration of $\mathrm{Au}_{3} A g-A u_{\mathrm{vac}} \mathrm{Au} \mathrm{u}_{3} \mathrm{Ag}$ (410), and Pt (111) surface. b, c Calculated free energy change of methanol oxidation intermediates on the $A u_{3} A g-A u_{v a c} A u_{3} A g$ (410), and Pt (111) surfaces, insets are the corresponding configurations of adsorbed intermediates. $\mathbf{d}$ Differential charge density of adsorbed $\mathrm{CO}$ on $\mathrm{Au}_{3} \mathrm{Ag}-\mathrm{Au}_{\mathrm{vac}}$, where the yellow and cyan contour with an iso-surface value of $0.0001 \mathrm{e} / \mathrm{bohr}^{3}$ indicate reduced and enhanced charge density, respectively. The $\mathrm{H}, \mathrm{O}, \mathrm{C}, \mathrm{Au}, \mathrm{Ag}$, and $\mathrm{Pt}$ atoms are in white, red, grey, yellow, light blue, and dark blue colors, respectively

(111) surfaces share the same reaction cascade with very similar free energy change of each elementary step and the same potential-determined step (pds) of ${ }^{\star} \mathrm{CH}_{3} \mathrm{OH} \rightarrow{ }^{\star} \mathrm{CH}_{2} \mathrm{OH}$ (Supplementary Fig. 19b). The pds free energy change for $\mathrm{Au}_{3} \mathrm{Ag}$ (111) and $\mathrm{Au}$ (111) are 0.80 and $0.79 \mathrm{eV}$ (Supplementary Table 5), respectively, suggesting that the introduction of $\mathrm{Ag}$ would not improve the intrinsic MOR activity of Au (111). However, after adopting crystalline defects such as the high-index facet of $\mathrm{Au}_{3} \mathrm{Ag}$ (410) and atomic vacancies of $\mathrm{Au}_{3} \mathrm{Ag}-\mathrm{Au}_{\mathrm{vac}}$, an alternate non-CO pathway (e.g., $\mathrm{CH}_{3} \mathrm{OH}(\mathrm{l}) \rightarrow{ }^{\star} \mathrm{CH}_{3} \mathrm{OH} \rightarrow{ }^{\star} \mathrm{CH}_{2} \mathrm{OH} \rightarrow{ }^{\star} \mathrm{CH}_{2} \mathrm{O} \rightarrow$ $\left.{ }^{\star} \mathrm{CHO} \rightarrow{ }^{\star} \mathrm{HCOOH} \rightarrow{ }^{\star} \mathrm{HCOO} \rightarrow \mathrm{CO}_{2}(\mathrm{~g})\right)$ is taken and the adsorption free energies of all the intermediates are reduced, especially on the $\mathrm{Au}_{3} \mathrm{Ag}$ (410) surface (Fig. 5b). Note that the pds is still ${ }^{\star} \mathrm{CH}_{3} \mathrm{OH} \rightarrow{ }^{\star} \mathrm{CH}_{2} \mathrm{OH}$ but with a much reduced free energy change of 0.62 and $0.47 \mathrm{eV}$ on the $\mathrm{Au}_{3} \mathrm{Ag}-\mathrm{Au}_{\mathrm{vac}}$ and $\mathrm{Au}_{3} \mathrm{Ag}$ (410) surfaces, respectively (Supplementary Table 5). This result strongly corroborates the experimental observations that the introduction of high-index atomic steps and crystalline defects can immensely lower the free energy barrier of pds, leading to greatly enhanced MOR activity.

On the $\mathrm{Pt}$ (111) surface, the reaction cascade follows the sequence $\quad \mathrm{CH}_{3} \mathrm{OH} \quad(\mathrm{l}) \rightarrow{ }^{*} \mathrm{CH}_{3} \mathrm{OH} \rightarrow{ }^{*} \mathrm{CH}_{2} \mathrm{OH} \rightarrow{ }^{\star} \mathrm{CHOH} \rightarrow$ ${ }^{\star} \mathrm{COH} \rightarrow{ }^{\star} \mathrm{CO} \rightarrow{ }^{\star} \mathrm{COOH} \rightarrow \mathrm{CO}_{2}(\mathrm{~g})$, with the further reduced adsorption free energy of ${ }^{\star} \mathrm{CH}_{2} \mathrm{OH}$ and the most negative free energy of ${ }^{\star} \mathrm{CO}$ (Fig. 5c). Thus, the pds is relocated to the elementary step of ${ }^{\star} \mathrm{CO} \rightarrow \mathrm{COOH}$ with an ultrahigh free energy change of $1.06 \mathrm{eV}$, in comparison to the pds $\left({ }^{*} \mathrm{CH}_{3} \mathrm{OH} \rightarrow\right.$ $\left.{ }^{\star} \mathrm{CH}_{2} \mathrm{OH}\right)$ of $0.80 \mathrm{eV}$ on $\mathrm{Au}_{3} \mathrm{Ag}(111), 0.62 \mathrm{eV}$ on $\mathrm{Au}_{3} \mathrm{Ag}-\mathrm{Au}_{\mathrm{vac}}$ and $0.47 \mathrm{eV}$ on $\mathrm{Au}_{3} \mathrm{Ag}$ (410). The observation of strong intermediates binding on $\mathrm{Pt}$ (111) with the highest ${ }^{\star} \mathrm{CO}$ activation barrier well explains its high activity but poor stability. Collectively, the above computational evidences suggest that introducing crystalline defects and low-coordination atoms onto the $\mathrm{Au}-\mathrm{Ag}$ surface enables to modulate the MOR reaction pathway, the intermediates binding energetics, and the ratedetermining steps, ultimately leading to enhanced MOR activity and stability.

Using the transition state search method corrected with working potentials relative to the reversible hydrogen electrode (RHE), we further calculated the activation barrier of each elementary step for $\mathrm{Pt}(111)$ and $\mathrm{Au}_{3} \mathrm{Ag}-\mathrm{Au}_{\mathrm{vac}}$ in account of the high computational cost of such calculations. The results are shown in Supplementary Fig. 22-25 and listed in Supplementary Tables 6 and 7. On the $\mathrm{Au}_{3} \mathrm{Ag}-\mathrm{Au}_{\mathrm{vac}}$ surface, the ratedetermining step (rds) is ${ }^{\star} \mathrm{CH}_{3} \mathrm{OH} \rightarrow{ }^{\star} \mathrm{CH}_{2} \mathrm{OH}$ with an activation barrier of $0.52 \mathrm{eV}$, which is also lower than that of Pt (111) with $0.58 \mathrm{eV}$ for the rds ${ }^{\star} \mathrm{CO} \rightarrow{ }^{\star} \mathrm{COOH}$. These kinetic studies are in good agreement with the above discussions on thermodynamics, and both are in line with the observed enhancement in MOR activity on $\mathrm{Au}_{3} \mathrm{Ag} \mathrm{NFs}$, rationalized by the low-coordination $\mathrm{Au}$ atoms on surface in mediating the intermediates binding and lowering the activation barriers. It is worth to mention the actual surface of $\mathrm{Au}_{3} \mathrm{Ag}$ NFs is much more complicated than these simple and exemplary defect models by encompassing rich steps, 
vacancies, dislocations, and grain boundaries, which should further promote its intrinsic activity. In fact, according to the Brønsted-Evans-Polanyi correlation ${ }^{61}$, the lower reaction free energy change of the elementary steps on $\mathrm{Au}_{3} \mathrm{Ag}$ (410) (Fig. 5b) might result in lower activation barriers than those observed on the $\mathrm{Au}_{3} \mathrm{Ag}-\mathrm{Au}_{\mathrm{vac}}$ surface.

Lastly, to further interrogate the CO-promoted $\mathrm{OH}^{-}$adsorption for the facilitation of subsequent deprotonation, we calculated the charge distribution of adjacent $\mathrm{Au}$ atoms after $\mathrm{CO}$ adsorption on the surface of $\mathrm{Au}_{3} \mathrm{Ag}-\mathrm{Au}_{\mathrm{vac}}$ through the differential charge density and bader charge analysis (Fig. 5d). The $\mathrm{Au}$ atoms around the adsorbed $\mathrm{CO}$ molecule such as Au37, $\mathrm{Au} 45$, and Au41 all contribute partial electron densities to CO, inducing the polarized $\mathrm{Au}^{\delta+}$ with $\Delta \mathrm{C}_{\mathrm{Au} 41}=0.0027, \Delta \mathrm{C}_{\mathrm{Au} 45}=$ 0.0567 , and $\Delta \mathrm{C}_{\mathrm{Au} 37}=0.0464$. These positively charged $\mathrm{Au}^{\delta+}$ atoms are conducive to $\mathrm{OH}^{-}$adsorption through Coulomb interactions, which in turn catalyzes the methanol $\beta$-hydrogen deprotonation ${ }^{34}$. As one can see from Fig. $5 \mathrm{~b}$ and Supplementary Fig. 19b, the step of $\beta$-hydrogen deprotonation (i.e., ${ }^{*} \mathrm{CH}_{3} \mathrm{OH} \rightarrow$ ${ }^{*} \mathrm{CH}_{2} \mathrm{OH}$ ) is the pds for all Au-based catalysts investigated in the current study. Therefore, the introduction of $\mathrm{CO}$ not only does not poison the $\mathrm{Au}_{3} \mathrm{Ag}$ NFs catalyst, but instead promotes the MOR activity.

\section{Discussion}

Taken together, the superior MOR activity of $\mathrm{Au}_{3} \mathrm{Ag}$ NFs can be mainly ascribed to the highly exposed active sites on the open $3 \mathrm{D}$ framework, and the bimetallic $\mathrm{Au}-\mathrm{Ag}$ alloying for generating abundant defects on the ultrathin edges and vertices, including low-coordination atoms, vacancies, dislocations, stacking faults, and lattice strains, etc. These structural defects enable to actively interact with the absorbents (both the methanol molecules and reaction intermediates) owing to the enriched surface electronic states and shifted d bands, which is evident from the XPS and XAFS analysis. In the d-band model proposed by Nørskov and co-workers ${ }^{62}$, the adsorption of rate-limiting intermediates is related to the electronic structure of the catalyst, where the valence $\mathrm{p}$ orbitals of the absorbents and intermediates form bonding and antibonding states with the metal d-band ${ }^{63-65}$. When the metal coordination number is low, the d-band width becomes narrower and the d-band center shifts up toward the Fermi level, pushing more of the antibonding states above $E_{\mathrm{f}}$, resulting in decreased occupation and more active interaction with the absorbents. The shift of $\mathrm{d}$ bands is further enhanced by the adsorption of oxygen-containing species, which on the surface of $\mathrm{Au}_{3} \mathrm{Ag} \mathrm{NFs}$ is synergistically promoted by lowered oxidation potentials and $\mathrm{CO}$ co-absorption. It has been reported that $\mathrm{CO}$ promoted $\mathrm{OH}^{-}$adsorption on gold efficiently catalyzes the betahydrogen elimination from $\mathrm{CH}_{3} \mathrm{OH}$, which is the rate-limiting step in typical Au-catalyzed MOR ${ }^{66,67}$. We also note that not only the $\mathrm{Au}$ defects but also the $\mathrm{Ag}$ atoms on $\mathrm{Au}_{3} \mathrm{Ag}$ NFs might conjunctively facilitate the $\mathrm{OH}^{-}$adsorption. Moreover, the positively polarized $\mathrm{Au}^{\delta+}$ sites have been reportedly shown enhanced Au oxidation activities ${ }^{68}$. As a synergy of all the above factors, the electrokinetics of MOR is greatly enhanced through the mediation of intermediate binding and corresponding activation barriers.

To summarize, in this work bimetallic $\mathrm{Au}_{3} \mathrm{Ag}$ nanoframes composed of ultrathin edges and vertices were synthesized using a facile one-pot method with high structural uniformity. By employing a comprehensive suite of structural and compositional characterization techniques, the morphological evolution and formation mechanism of these nanoframes were well elucidated. CS-TEM revealed rich crystalline defects on the nanoframes, resulting in modulated electronic structure with characteristic
$\mathrm{Au}^{\delta+}$ polarization and prominent shift of $\mathrm{d}$ bands. Elaborative voltammetry measurements unveiled higher electrochemical activity of the defect-rich $\mathrm{Au}_{3} \mathrm{Ag}$ nanoframes in $\mathrm{OH}^{-}$adsorption, surface oxidation, as well as $\mathrm{CO}$ stripping. Consequently, $\mathrm{Au}_{3} \mathrm{Ag}$ NFs demonstrated extraordinary MOR activities with an onset potential of only $0.3 \mathrm{~V}$ and a high SA of $3.38 \mathrm{~mA} \mathrm{~cm}^{-2}, 3.9$ times that of the commercial $\mathrm{Pt} / \mathrm{C}$. The superior MOR of $\mathrm{Au}_{3} \mathrm{Ag} \mathrm{NFs}$ is mainly attributed to the highly exposed active sites, abundant surface defects, and modulated electronic structure, effectively mediating the reaction pathway, intermediates binding, and ratedetermining steps for improved MOR electrokinetics. What is more, MOR catalyzed by the $\mathrm{Au}_{3} \mathrm{Ag} \mathrm{NFs}$ has been shown counter-intuitively promoted by $\mathrm{CO}$ owing to the much lowered $\mathrm{CO}$-stripping potential and synergistic $\mathrm{CO}-\mathrm{OH}^{-}$interaction on the catalyst surface. Through the tailoring of Au nanostructure into defect-rich frameworks, this study signifies the approach by mediating surface electronic states to impart unprecedented catalytic activities.

\section{Methods}

Chemicals. Silver nitrate $\left(\mathrm{AgNO}_{3}, \geq 99.0 \%\right)$, cuprous chloride $(\mathrm{CuCl}, \geq 98.0 \%)$, octadecylamine (ODA, $\geq 90 \%$ ), and cetyltrimethylammonium bromide (CTAB, $\geq 99.0 \%$ ) are purchased from Shanghai Aladdin Bio-Chem Technology Co., Ltd. Chloroauric acid tetrahydrate $\left(\mathrm{HAuCl}_{4} \cdot 4 \mathrm{H}_{2} \mathrm{O}, \geq 47.8 \%\right.$ Au basis), ethanol $\left(\mathrm{C}_{2} \mathrm{H}_{6} \mathrm{O}\right.$, $\geq 99.7 \%)$, cyclohexane $\left(\mathrm{C}_{6} \mathrm{H}_{12}, \geq 99.0 \%\right)$, dichloromethane $\left(\mathrm{CH}_{2} \mathrm{Cl}_{2} \geq 99.5 \%\right)$, methanol $\left(\mathrm{CH}_{4} \mathrm{O}, \geq 99.5 \%\right)$, and potassium hydroxide $(\mathrm{KOH}, \geq 99.0 \%)$ are purchased from Sinopharm Chemical Reagent Co., Ltd. All chemicals were used without further purification. Milli-Q water $(>18.0 \mathrm{M} \Omega \mathrm{cm})$ was purified with a Sartorius arium mini ultrapure water system.

Synthesis of $\mathbf{A u}_{\mathbf{3}} \mathbf{A g}$ nanoframes. Totally, $0.073 \mathrm{~g} \mathrm{CTAB}$ were dissolved in $10 \mathrm{ml}$ ODA which kept at $125^{\circ} \mathrm{C}$ under nitrogen $\left(\mathrm{N}_{2}\right)$ for $1 \mathrm{~h}$. Then $0.02 \mathrm{~g} \mathrm{AgNO}_{3}$ and $0.01 \mathrm{~g} \mathrm{CuCl}$ were added into this system. After $36 \mathrm{~min}$ of magnetically stirring, $0.01 \mathrm{~g} \mathrm{HAuCl}_{4} \cdot 4 \mathrm{H}_{2} \mathrm{O}$ were quickly injected, and the solution was kept for another $10 \mathrm{~min}$. When the reaction was finished, the reaction flask was carefully transferred into a water bath of $60^{\circ} \mathrm{C}$ in order to quench the growth process, followed by addition of $40 \mathrm{~mL}$ ethanol and kept for $6 \mathrm{~h}$ without magnetic stirring. The produced $\mathrm{Au}_{3} \mathrm{Ag}$ nanoframe was further washed 15 times with ethanol and dichloromethane mixed solution, and redispersed in cyclohexane.

Characterization. The crystal structure was characterized by powder X-ray diffraction (XRD, Bruker AXS D8 Advance diffractometer with Cu Ka source). The surface morphology and microstructure were observed using a dual-beam electron microscope (SEM, FEI Scios) and a field-emission transmission electron microscope (TEM, FEI TECNAI G2 F20 $200 \mathrm{kV}$ ) equipped with an energy-dispersive $\mathrm{X}$-ray analyzer (EDX). Spherical-aberration-corrected TEM (Cs-corrected TEM, FEI Titan Themis Cubed G2 300) was used to inspect atomic orientation of edges and vertexes in $\mathrm{Au}_{3} \mathrm{Ag}$ nanoframe. Surface elements were probed by X-ray photoelectron spectroscopy (XPS, Thermo Fisher, Escalab 250Xi) using a monochromatic $\mathrm{Al} \mathrm{Ka}(1486.6 \mathrm{eV}) \mathrm{X}$-ray source, with all binding-energy values calibrated with C $1 \mathrm{~s} 1 / 4284.6 \mathrm{eV}$. Inductively coupled plasma optical emission spectroscopy (ICP-OES) was utilized for total composition analysis with PerkinElmer Optima 8000. The Au L $\mathrm{L}_{3}$-edge XAFS spectra were recorded by QEXAFS at Beamline 44A at the Taiwan Photon Source (TPS) and transmission mode were applied to all of the samples. The raw data and the fittings were carried out by using IFEFFIT software packages according to the standard analysis procedures ${ }^{69}$.

Electrochemical characterization. In all, $0.1 \mathrm{mg}$ AuAg nanostructures was suspended in a solution containing $0.5 \mathrm{ml}$ ethanol, $40 \mathrm{ul}$ of $5 \mathrm{wt} \%$ Nafion solution and 5 ug Ketjen Black by ultrasonication for 30-40 min to complete the loading process. To fabricate working electrode, a quantity of $50 \mathrm{ul}$ of the suspension was drop-casted on glassy carbon (GC) electrode surface (loading amount was about $0.5 \mathrm{mg} / \mathrm{cm}^{2}$ ). The $\mathrm{c}$ was air dried for $1 \mathrm{~h}$ at room temperature before use. All the electrochemical measurements were performed in a standard three-electrode cell at room temperature using an electrochemical workstation $(\mathrm{CHI} 660 \mathrm{E})$. The Pt wire was used as the counter electrode, with the $\mathrm{Ag} / \mathrm{AgCl}$ electrode (filled with saturated $\mathrm{KCl})$ as the reference electrode. Prior to catalyst loading, the GC electrode was carefully polished with $1.0,0.3$ and $0.05 \mu \mathrm{m}$ alumina powder in sequence, and cleaned by sonication in ethanol and deionized water. The electrolyte was $0.5 \mathrm{M}$ $\mathrm{KOH}$ and $2 \mathrm{M}$ methanol $(\mathrm{PH}=13.3)$ bubbled with nitrogen for $30 \mathrm{~min}$ prior to MOR measurements. All the potentials were converted to the potentials referring to the RHE, according to $\mathrm{E}$ (vs. RHE) $=\mathrm{E}(\mathrm{vs} . \mathrm{Ag} / \mathrm{AgCl})+0.059 \mathrm{pH}+0.198$. 
Estimation of electrochemical surface area. CO stripping was used for determination of the electrochemical surface area. First, the catalyst was subjected to an electrochemical cleaning procedure by cycling the electrode in $\mathrm{N}_{2}$ purged $0.1 \mathrm{M}$ $\mathrm{HClO}_{4}$ for 30 cycles in a potential window of -0.2 to $1.5 \mathrm{~V}$ at a scan rate of $100 \mathrm{mV} \mathrm{s}^{-1}$. Then CO (>99.99\% purity) gas was bubbled in the electrolyte for $30 \mathrm{~min}$ while holding the electrode potential at $-0.1 \mathrm{~V}$ to allow for the adsorption of a monolayer of $\mathrm{CO}$ molecules. Afterward, dissolved $\mathrm{CO}$ was removed by bubbling the electrolyte for 20 min with $\mathrm{N}_{2}$ gas. Finally, the voltammogram for CO stripping was recorded in a potential window of -0.2 to $1.5 \mathrm{~V}$ for two consecutive cycles at a scan rate of $20 \mathrm{mV} \mathrm{s}^{-1}$. The first cycle is to record the $\mathrm{CO}_{\text {ads }}$ stripping and the next cycle to ensure the complete stripping of $\mathrm{CO}_{\mathrm{ads}}$ during the first cycle.

$$
\mathrm{ECSA}=\frac{Q_{\mathrm{CO}}}{Q_{0} \times m} .
$$

Where $Q_{\mathrm{CO}}$ is the integrated charge consumed during the $\mathrm{CO}_{\mathrm{ads}}$ oxidation, $Q_{0}$ is the standard charge required for oxidation of a $\mathrm{CO}_{\mathrm{ads}}$ monolayer on a Pt surface with a value of $420 \mu \mathrm{C} \mathrm{cm}^{-2}$, and Au with $450 \mu \mathrm{Ccm}^{-2} . m$ was the Au or Pt mass on the working electrode as determined by ICP-OES

\section{Data availability}

The data that support the findings of this study are available from the authors upon request.

Received: 25 March 2019 Accepted: 1 August 2019

Published online: 22 August 2019

\section{References}

1. Steele, B. C. \& Heinzel, A. Materials for fuel cell technologies. Nature 414, 345-352 (2001).

2. Shi, L., Xu, A., Pan, D. \& Zhao, T. Aqueous proton-selective conduction across two-dimensional graphyne. Nat. Commun. 10, 1165 (2019).

3. Huang, L. et al. Shape-control of Pt-Ru nanocrystals: tuning surface structure for enhanced electrocatalytic methanol oxidation. J. Am. Chem. Soc. 140, 1142-1147 (2018).

4. Li, C. et al. Dendritic defect-rich palladium-copper-cobalt nanoalloys as robust multifunctional non-platinum electrocatalysts for fuel cells. Nat. Commun. 9, 3702 (2018).

5. Zhang, W. et al. Ultrathin PtNiM $(\mathrm{M}=\mathrm{Rh}$, Os, and Ir) nanowires as efficient fuel oxidation electrocatalytic materials. Adv. Mater. 31, e1805833 (2019).

6. Yu, Y., Wang, X. \& Lim, K. H. A DFT study on the adsorption of formic acid and its oxidized intermediates on (100) facets of $\mathrm{Pt}, \mathrm{Au}$, monolayer and decorated Pt@Au surfaces. Catal. Lett. 141, 1872-1882 (2011).

7. Hunt, S. T. et al. Self-assembly of noble metal monolayers on transition metal carbide nanoparticle catalysts. Science 352, 974-978 (2016).

8. Yang, P. et al. Solvothermal synthesis of alloyed ptni colloidal nanocrystal clusters (CNCs) with enhanced catalytic activity for methanol oxidation. $A d v$. Funct. Mater. 28, 1704774 (2018).

9. Xia, B. Y., Wu, H. B., Wang, X. \& Lou, X. W. One-pot synthesis of cubic $\mathrm{PtCu} 3$ nanocages with enhanced electrocatalytic activity for the methanol oxidation reaction. J. Am. Chem. Soc. 134, 13934-13937 (2012).

10. Qi, Z. et al. Sub-4 nm PtZn intermetallic nanoparticles for enhanced mass and specific activities in catalytic electrooxidation reaction. J. Am. Chem. Soc. 139, 4762-4768 (2017).

11. Kelly, C. H. W. et al. Understanding the effect of Au in Au-Pd bimetallic nanocrystals on the electrocatalysis of the methanol oxidation reaction. J. Phys. Chem. C 122, 21718-21723 (2018).

12. Chen, Z. et al. PdCu alloy flower-like nanocages with high electrocatalytic performance for methanol oxidation. J. Phys. Chem. C 122, 8976-8983 (2018).

13. Huang, W. et al. 2D PdAg alloy nanodendrites for enhanced ethanol electroxidation. Adv. Mater. 30, 1706962 (2018).

14. Mandal, K., Bhattacharjee, D., Roy, P. S., Bhattacharya, S. K. \& Dasgupta, S. Room temperature synthesis of $\mathrm{Pd}-\mathrm{Cu}$ nanoalloy catalyst with enhanced electrocatalytic activity for the methanol oxidation reaction. Appl. Catal. A 492, 100-106 (2015).

15. Haruta, M. Catalysis: gold rush. Nature 437, 1098-1099 (2005).

16. Rodriguez, P., Koverga, A. A. \& Koper, M. T. Carbon monoxide as a promoter for its own oxidation on a gold electrode. Angew. Chem. Int. Ed. Engl. 49, 1241-1243 (2010).

17. Roberts, J. Jr \& Sawyer, D. J. E. A. Electrochemical oxidation of carbon monoxide at gold electrodes. Electrochim. Acta 10, 989-1000 (1965).

18. Zope, B. N., Hibbitts, D. D., Neurock, M. \& Davis, R. J. Reactivity of the gold/water interface during selective oxidation catalysis. Science 330, 74-78 (2010).
19. Xu, B., Liu, X., Haubrich, J. \& Friend, C. M. Vapour-phase gold-surfacemediated coupling of aldehydes with methanol. Nat. Chem. 2, 61-65 (2010).

20. Herzing, A. A., Kiely, C. J., Carley, A. F., Landon, P. \& Hutchings, G. J. Identification of active gold nanoclusters on iron oxide supports for $\mathrm{CO}$ oxidation. Science 321, 1331-1335 (2008).

21. Wang, Z. et al. Free-standing nanoporous gold for direct plasmon enhanced electro-oxidation of alcohol molecules. Nano Energy 56, 286-293 (2019).

22. Widmann, D. \& Behm, R. J. Activation of molecular oxygen and the nature of the active oxygen species for $\mathrm{CO}$ oxidation on oxide supported $\mathrm{Au}$ catalysts. Acc. Chem. Res. 47, 740-749 (2014).

23. Hvolbæk, B. et al. Catalytic activity of Au nanoparticles. Nano Today 2, 14-18 (2007).

24. Fang, J. et al. A general soft-enveloping strategy in the templating synthesis of mesoporous metal nanostructures. Nat. Commun. 9, 521 (2018).

25. Wittstock, A., Zielasek, V., Biener, J., Friend, C. M. \& Baumer, M. Nanoporous gold catalysts for selective gas-phase oxidative coupling of methanol at low temperature. Science 327, 319-322 (2010).

26. Wang, Z. et al. Engineering the internal surfaces of three-dimensional nanoporous catalysts by surfactant-modified dealloying. Nat. Commun. 8 1066 (2017)

27. Pedireddy, S. et al. One-step synthesis of zero-dimensional hollow nanoporous gold nanoparticles with enhanced methanol electrooxidation performance. Nat. Commun. 5, 4947 (2014)

28. Fujita, T. et al. Atomic origins of the high catalytic activity of nanoporous gold. Nat. Mater. 11, 775-780 (2012).

29. Chen, C. et al. Highly crystalline multimetallic nanoframes with threedimensional electrocatalytic surfaces. Science 343, 1339-1343 (2014).

30. Wu, Y. et al. Sophisticated construction of Au islands on Pt-Ni: an ideal trimetallic nanoframe catalyst. J. Am. Chem. Soc. 136, 11594-11597 (2014).

31. Ahn, J., Wang, D., Ding, Y., Zhang, J. \& Qin, D. Site-selective carving and Codeposition: transformation of $\mathrm{Ag}$ nanocubes into concave nanocrystals encased by Au-Ag alloy frames. ACS Nano. 12, 298-307 (2018).

32. Mahmoud, M. A. \& El-Sayed, M. A. Gold nanoframes: very high surface plasmon fields and excellent near-infrared sensors. J. Am. Chem. Soc. 132, 12704-12710 (2010)

33. McEachran, M. et al. Ultrathin gold nanoframes through surfactant-free templating of faceted pentagonal silver nanoparticles. J. Am. Chem. Soc. 133, 8066-8069 (2011).

34. Rodriguez, P., Kwon, Y. \& Koper, M. T. The promoting effect of adsorbed carbon monoxide on the oxidation of alcohols on a gold catalyst. Nat. Chem. 4, 177-182 (2011)

35. Hong, X., Wang, D., Cai, S., Rong, H. \& Li, Y. Single-crystalline octahedral Au-Ag nanoframes. J. Am. Chem. Soc. 134, 18165-18168 (2012).

36. Tao, A., Sinsermsuksakul, P. \& Yang, P. Polyhedral silver nanocrystals with distinct scattering signatures. Angew. Chem. Int. Ed. Engl. 45, 4597-4601 (2006).

37. Xia, Y., Xia, X. \& Peng, H. C. Shape-controlled synthesis of colloidal metal nanocrystals: thermodynamic versus kinetic products. J. Am. Chem. Soc. 137, 7947-7966 (2015)

38. Langille, M. R., Personick, M. L., Zhang, J. \& Mirkin, C. A. Defining rules for the shape evolution of gold nanoparticles. J. Am. Chem. Soc. 134, 14542-14554 (2012).

39. Gonzalez, E., Arbiol, J. \& Puntes, V. F. Carving at the nanoscale: sequential galvanic exchange and Kirkendall growth at room temperature. Science 334, 1377-1380 (2011).

40. Personick, M. L. \& Mirkin, C. A. Making sense of the mayhem behind shape control in the synthesis of gold nanoparticles. J. Am. Chem. Soc. 135, 18238-18247 (2013)

41. Au, L., Lu, X. \& Xia, Y. A comparative study of galvanic replacement reactions involving $\mathrm{Ag}$ nanocubes and $\mathrm{AuCl}(2)$ or $\mathrm{AuCl}(4)$. Adv. Mater. 20, 2517-2522 (2008).

42. Van Hove, M. \& Somorjai, G. J. S. S. A new microfacet notation for highMiller-index surfaces of cubic materials with terrace, step and kink structures. Surf. Sci. 92, 489-518 (1980).

43. Quan, Z., Wang, Y. \& Fang, J. High-index faceted noble metal nanocrystals. Acc. Chem. Res. 46, 191-202 (2013).

44. Edagawa, K., Suzuki, T. \& Takeuchi, S. Motion of a screw dislocation in a twodimensional Peierls potential. Phys. Rev. B 55, 6180-6187 (1997).

45. Ahmadi, M., Behafarid, F., Cui, C., Strasser, P. \& Cuenya, B. R. Long-range segregation phenomena in shape-selected bimetallic nanoparticles: chemical state effects. ACS Nano 7, 9195-9204 (2013).

46. Zou, L. et al. Dislocation nucleation facilitated by atomic segregation. Nat. Mater. 17, 56-63 (2018).

47. Sham, T. K., Perlman, M. L. \& Watson, R. E. Electronic behavior in alloys: Gold-non-transition-metal intermetallics. Phys. Rev. B. 19, 539-545 (1979). 
48. Zhang, P. \& Sham, T. K. X-ray studies of the structure and electronic behavior of alkanethiolate-capped gold nanoparticles: the interplay of size and surface effects. Phys. Rev. Lett. 90, 245502 (2003).

49. Gan, L. Y. \& Zhao, Y. J. Charge effect in S enhanced CO adsorption: a theoretical study of $\mathrm{CO}$ on $\mathrm{Au}, \mathrm{Ag}, \mathrm{Cu}$, and $\mathrm{Pd}$ (111) surfaces coadsorbed with S, O, Cl, and Na. J. Chem. Phys. 133, 094703 (2010).

50. Brown, M. A. et al. Initial formation of positively charged gold on $\mathrm{MgO}(001)$ thin films: identification by experiment and structural assignment by theory. J. Phys. Chem. C 115, 10114-10124 (2011).

51. Boronat, M., Concepcion, P. \& Corma, A. Unravelling the nature of gold surface sites by combining IR spectroscopy and DFT calculations. implications in catalysis. J. Phys. Chem. C 113, 16772-16784 (2009).

52. Strasser, P. et al. Lattice-strain control of the activity in dealloyed core-shell fuel cell catalysts. Nat. Chem. 2, 454-460 (2010).

53. Bagus, P. S. \& Pacchioni, G. On the origin of bonding and vibrational frequency shifts for $\mathrm{CO}$ adsorbed on neutral, cationic and anionic gold clusters. J. Phys. Confer. Ser. 117, 012003 (2008).

54. Shibata, T. et al. Size-dependent spontaneous alloying of Au-Ag nanoparticles. J. Am. Chem. Soc. 124, 11989-11996 (2002).

55. Liu, F., Wechsler, D. \& Zhang, P. Alloy-structure-dependent electronic behavior and surface properties of Au-Pd nanoparticles. Chem. Phys. Lett. 461, 254-259 (2008).

56. Liu, Z. L., Ling, X. Y., Su, X. D. \& Lee, J. Y. Carbon-supported Pt and PtRu nanoparticles as catalysts for a direct methanol fuel cell. J. Phys. Chem. B 108 , 8234-8240 (2004).

57. Angelucci, C. A., Ambrosio, R. C. \& Gewirth, A. A. Origins of less noble behavior by Au during CO adsorption. ACS Catal. 8, 2247-2252 (2018).

58. Liu, C. et al. CO self-promoting oxidation on nanosized gold clusters: triangular Au3 active site and $\mathrm{CO}$ induced O-O scission. J. Am. Chem. Soc. 135, 2583-2595 (2013).

59. Kwon, H. C. et al. Carbon monoxide as a promoter of atomically dispersed platinum catalyst in electrochemical hydrogen evolution reaction. J. Am. Chem. Soc. 140, 16198-16205 (2018)

60. Beller, M., Cornils, B., Frohning, C. D. \& Kohlpaintner, C. W. Progress in hydroformylation and carbonylation. J. Mol. Catal. A 104, 17-85 (1995).

61. Ferrin, P. et al. Modeling ethanol decomposition on transition metals: a combined application of scaling and Brønsted-Evans-Polanyi relations. J. Am. Chem. Soc. 131, 5809-5815 (2009).

62. Hammer, B. \& Nørskov, J. K. Theoretical surface science and catalysiscalculations and concepts. Adv. Catal. 45, 71-129 (2000).

63. Norskov, J. K. et al. The nature of the active site in heterogeneous metal catalysis. Chem. Soc. Rev. 37, 2163-2171 (2008).

64. Nilsson, A. et al. The electronic structure effect in heterogeneous catalysis. Catal. Lett. 100, 111-114 (2005).

65. Norskov, J. K., Bligaard, T., Rossmeisl, J. \& Christensen, C. H. Towards the computational design of solid catalysts. Nat. Chem. 1, 37-46 (2009).

66. Chen, A. C. \& Lipkowski, J. Electrochemical and spectroscopic studies of hydroxide adsorption at the $\mathrm{Au}(111)$ electrode. J. Phys. Chem. B 103, 682-691 (1999).

67. Yan, S., Zhang, S., Lin, Y. \& Liu, G. Electrocatalytic performance of gold nanoparticles supported on activated carbon for methanol oxidation in alkaline solution. J. Phys. Chem. C 115, 6986-6993 (2011).

68. Duan, X. et al. Sulfur moiety as a double-edged sword for realizing ultrafine supported metal nanoclusters with a cationic nature. ACS. Appl. Mater. Inter. 12, 11317-11326 (2019).
69. Newville, M. IFEFFIT: interactive XAFS analysis and FEFF fitting. J. Synchrotron Radiat. 8, 322-324 (2001).

\section{Acknowledgements}

This work is supported by Natural Science Foundation of China (No. 21701118), Natura Science Foundation of Jiangsu Province (Nos. BK20161209 and BK20160323), Natural Science Research Project of Jiangsu Higher Education Institutions (18KJA480004), the Key Technology Initiative of Suzhou Municipal Science and Technology Bureau (SYG201748), and Priority Academic Program Development (PAPD) of Jiangsu Higher Education Institutions. We also thank Chih-Wen Pao, Jeng-Lung Chen, and Chi-Liang Chen (Beamline 44A, Taiwan Light Source (TPS) for excellent technical support and valuable discussion. The project also was supported by Soochow University-Western University Centre for Synchrotron Radiation Research.

\section{Author contributions}

Y.P. conceived the idea and led the project. L.X. and X.Z. designed and performed the majority of the experiments. P.H. helped on the preliminary test on the electrocatalysis performance. L.Z. and M.H.R. took the Cs-TEM images and analyzed the data. X.C., Z.S and W.Y. carried out the DFT calculations. D.Z. and S.W. carried out XAFs characterizations. H.J. and H.S. helped on the SEM characterizations. Y.L. took the TEM images. Z.D. devoted to the electrochemical data analysis. L.X., Z.D. and Y.P. wrote the paper. All the authors have discussed the results.

\section{Additional information}

Supplementary Information accompanies this paper at https://doi.org/10.1038/s41467 019-11766-w.

Competing interests: The authors declare no competing interests.

Reprints and permission information is available online at http://npg.nature.com/ reprintsandpermissions/

Peer review information: Nature Communications would like to thank Jixiang Fang and other, anonymous, reviewers for their contributions to the peer review of this work.

Publisher's note: Springer Nature remains neutral with regard to jurisdictional claims in published maps and institutional affiliations.

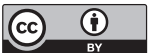

Open Access This article is licensed under a Creative Commons Attribution 4.0 International License, which permits use, sharing, adaptation, distribution and reproduction in any medium or format, as long as you give appropriate credit to the original author(s) and the source, provide a link to the Creative Commons license, and indicate if changes were made. The images or other third party material in this article are included in the article's Creative Commons license, unless indicated otherwise in a credit line to the material. If material is not included in the article's Creative Commons license and your intended use is not permitted by statutory regulation or exceeds the permitted use, you will need to obtain permission directly from the copyright holder. To view a copy of this license, visit http://creativecommons.org/ licenses/by/4.0/

(c) The Author(s) 2019 